bioRxiv preprint doi: https://doi.org/10.1101/2022.02 17.480574 this version posted February 22,2022 . The copyright holder for this preprint (which was not certified by peer review) is the author/funder, who has granted bioRxiv a license to display the preprint in perpetuity. It is made available under aCC-BY-NC-ND 4.0 International license.

\title{
Prefrontally Modulated Vagal Tone Inhibits Inflammatory Responses to Prevent Telomere Damage in Healthy Participants
}

\author{
Torvald F. Ask ${ }^{1,2^{*}}$, Stefan Sütterlin ${ }^{1,3}$ \\ ${ }^{1}$ Faculty for Health, Welfare and Organization, Østfold University College, Halden, Norway \\ ${ }^{2}$ Department of Information Security and Communication Technology, Norwegian University \\ of Science and Technology \\ ${ }^{3}$ Faculty of Computer Science, Albstadt-Sigmaringen University, Sigmaringen, Germany
}

*Corresponding author
torvaldfask@gmail.com

\begin{abstract}
Background: Accumulated senescent cells are proposed to be one of the main drivers of age-related pathology through disruption of tissue structure and function. We recently proposed the Neuro-ImmunoSenescence Integrative Model (NISIM; Ask et al., 2018) which relates prefrontally modulated vagal tone and subsequent balance between vagal and sympathetic input to the spleen to inflammatory responses leading to generation of reactive oxygen species and oxidative telomere damage. The NISIM is based on converging evidence and argues for the existence of a prefrontal cortex-autonomic nervous system-spleen (PAS) axis, suggesting that the inflammation that induces reactive oxygen species-generation is downstream of this axis. Aim: In this study, we aim to assess inflammation as a mediator in the relationship between prefrontally modulated vagal tone and leukocyte telomere length to test the hypothesis that PAS axis dysregulation accelerates cellular aging. We also assess the relationship between a recently proposed index of vagal immunomodulation (vagal tone/inflammation ratio; NIM index; Gidron et al., 2018) and telomere length, and compare results between the NIM index and vagal tone as predictors of telomere length. Methods: This study uses participant data from a large nationally representative longitudinal study since 1974 with a total of 45,000 Norwegian residents so far. A sub-sample of 1372 participants from which vagal tone, C Reactive Protein, and leukocyte telomere length could be obtained were included in the study. Relationships were analyzed with hierarchical multiple linear regression using either vagal tone and $\mathrm{C}$ Reactive Protein or the NIM index to predict telomere length. Sleeping problems, tobacco use status, alcohol use status, time since last meal, and symptoms of depression were included as control variables. Results: In the mediation analysis, vagal tone was a significant positive predictor of telomere length, while $\mathrm{C}$ Reactive Protein was a significant negative predictor of telomere length. This relationship remained significant when individually controlling for some but not all confounding variables. The NIM index was a significant positive predictor of telomere length. This relationship remained significant when controlling for all confounding variables except one. In a reduced dataset excluding all participants where confounders were present, the NIM index remained a significant predictor of telomere length. Conclusion: This is the first study suggesting that PAS axis activity is associated with telomere length thus supporting the NISIM. Results indicate that the NIM index is a more sensitive indicator of PAS axis activity than vagal tone and $\mathrm{C}$ Reactive Protein in isolation. Clinical relevance and suggestions for future research are discussed.
\end{abstract}

Keywords: vagally mediated heart rate variability, inflammation, $\mathrm{C}$ reactive protein, telomere length, the neuro-immuno-senescence integrative model, the prefrontal cortex-autonomic nervous system-spleen axis, neuroimmunomodulation, cellular senescence, vagal tone 
bioRxiv preprint doi: https://doi.org/10.1101/2022.02.17.480574; this version posted February 22, 2022. The copyright holder for this preprint (which was not certified by peer review) is the author/funder, who has granted bioRxiv a license to display the preprint in perpetuity. It is made available under aCC-BY-NC-ND 4.0 International license.

\section{$1 \quad$ Introduction}

In this paper, we test the previously postulated hypothesis that inflammation mediates the relationship between vagally mediated heart rate variability (vmHRV) and telomere length (Ask, Lugo, \& Sütterlin, 2018) to elucidate the mechanisms linking individual differences in psychophysiological stress regulation capacity to aging and age-related pathophysiology. We also test whether a recently proposed index for vagal immunomodulation (Gidron et al., 2018) is associated with telomere length and we discuss it with respect to the mediation analysis. The shift towards considering aging as a disease has prompted increasing efforts to understand its many underlying mechanisms and their subsequent role in degenerating pathologies (e.g. Campisi, 2000, 2013; Kane \& Sinclair, 2019). These efforts converge on the ambition that if humans can fully understand the physiological drivers of aging then perhaps medical- and behavioral interventions can be developed such that age-related pathologies can be eradicated altogether.

Aging entails a progressive loss of physiological integrity resulting in impaired function and increased vulnerability to death, with hallmarks being genomic instability, telomere attrition, epigenetic alterations, loss of proteostasis, deregulated nutrient-sensing, mitochondrial dysfunction, stem cell exhaustion, cellular senescence, and altered intercellular communication (Figure 1, a; López-Otín et al., 2013). These hallmarks can be divided into three categories: primary hallmarks (causes of damage), antagonistic hallmarks (responses to damage), and integrative hallmarks (culprits of the [aging] phenotype).

a

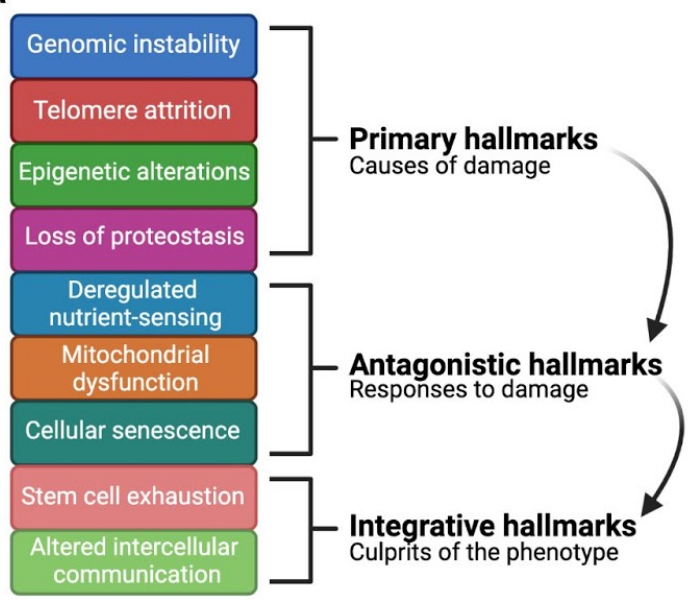

b

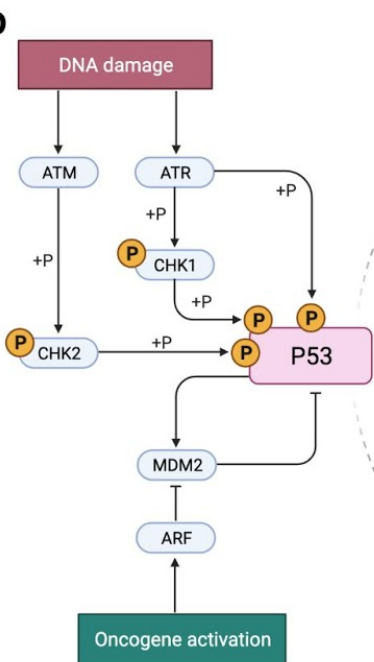

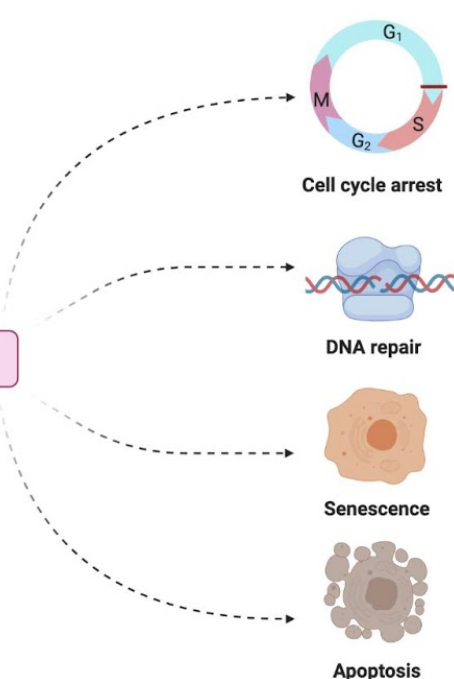

Figure 1 | The hallmarks of aging and the DNA damage response. a The three categories of the hallmarks of aging. Modified with permission from López-Otín et al. (2013). b The P53-mediated DNA damage response pathway. ATM $=$ ATM Serine/threonine-protein kinase. ATR $=$ ATR Serine/threonine-protein kinase. CHK1 $=$ Checkpoint kinase 1. CHK2 $=$ Checkpoint kinase 2. $\mathrm{P} 53=$ protein $53 . \mathrm{MDM} 2=$ Mouse double minute $2 . \mathrm{ARF}=$ Alternative reading frame. Created with BioRender.com.

Cellular senescence, also known as cellular aging, is secondary to some of these hallmarks, most notably genomic instability, telomere attrition, and mitochondrial dysfunction (Campisi, 2000, 2013). Following DNA damage, a network cascade of proteins is activated as 
bioRxiv preprint doi: https://doi.org/10.1101/2022.02.17.480574; this version posted February 22, 2022. The copyright holder for this preprint (which was not certified by peer review) is the author/funder, who has granted bioRxiv a license to display the preprint in perpetuity. It is made available under aCC-BY-NC-ND 4.0 International license.

part of the DNA damage response (DDR), leading to the phosphorylation of P53. Whether DNA-damage induced P53 activation will result in cellular senescence or another response such as DNA repair or apoptosis depends on the persistence of the DDR signal and the cellular stressor (Campisi, 2000, 2013; Figure 1, b). Due to being resistant to apoptosis, senescent cells accumulate with age. Some senescent cells start secreting a wide range of ligands including inflammatory molecules and growth factors that over time promote disruption in tissue structure and function, thus altering intercellular communication (Campisi, 2000, 2013; Tchkonia et al., 2013). This is known as the senescence-associated secretory phenotype and is a suggested driver of age-related pathologies such as neurodegenerative diseases (Baker et al., 2011; Chinta et al., 2015) and cancer (Bissel et al., 2005; Rao and Jackson, 2016). Individual anatophysiological factors driving the antecedents to cellular senescence are still poorly understood.

\subsection{The Neuro-Immuno-Senescence Integrative Model (NISIM) on the relationship between prefrontally modulated vagal tone and cellular senescence}

In a seminal paper, Epel and colleagues (2004) made the pioneering discovery that psychological stress is related to shorter telomere length, an antecedent to cellular senescence (Campisi, 2000, 2013). While being a critical contribution to our understanding of how psychological stress relates to ill-health, the specific mechanisms relating these phenomena have remained rather elusive for the remaining decade-plus despite considerable scientific inquiry (e.g. Epel et al., 2009; Morey et al., 2015). In an effort to bridge this gap, we recently proposed a model (Figure 1) outlining specific anato-physiological mechanisms relating psychological stress regulation to cellular senescence, and subsequently, age-related pathology (Ask, Lugo, \& Sütterlin, 2018). The model is largely based on the prefrontal component of the central-autonomic network, the immuno reflex (or cholinergic anti-inflammatory pathway; Tracey, 2002), and the molecular cell biology related to generation of reactive oxygen species (ROS; e.g. Schreck \& Bauerle, 1994). In this model, termed the Neuro-Immuno-Senescence Integrative Model (NISIM; Ask et al., 2018), the prefrontal capacity for modulation of vagal activation, quantified as vmHRV (Thayer \& Lane, 2000; Thayer et al., 2012) during exposure to psychological stress, consequently affect the balance of vagal and sympathetic input to the spleen (Tracey, 2002). Low capacity for prefrontal vagal modulation translates to low vmHRV (Thayer \& Lane, 2000), indicating reduced vagal input to the spleen and increased inflammation (Williams et al., 2019). Increased inflammatory load, such as increased levels of Interleukin-6 (IL-6), C-Reactive Protein (CRP), and Tumor Necrosis Factor $\alpha$ (TNF- $\alpha$ ) is negatively associated with telomere length (Fitzpatrick et al., 2006; Masi et al., 2012; O'Donovan et al., 2011; Wong et al., 2014), while indicators of vagal tone such as respiratory sinus arrhythmia (Kroenke, 2011) and vmHRV is positively associated with telomere length (Perseguini et al., 2015; Streltsova et al., 2017; Woody et al., 2017; Zalli et al., 2013). Together, the outlined above mechanisms are how the NISIM relates psychological stress to cellular senescence in a dynamic framework that accounts for inter-individual differences in the expression of agerelated phenotypes. 
bioRxiv preprint doi: https://doi.org/10.1101/2022.02 17.480574 this version posted February 22, 2022. The copyright holder for this preprint (which was not certified by peer review) is the author/funder, who has granted bioRxiv a license to display the preprint in perpetuity. It is made available under aCC-BY-NC-ND 4.0 International license.

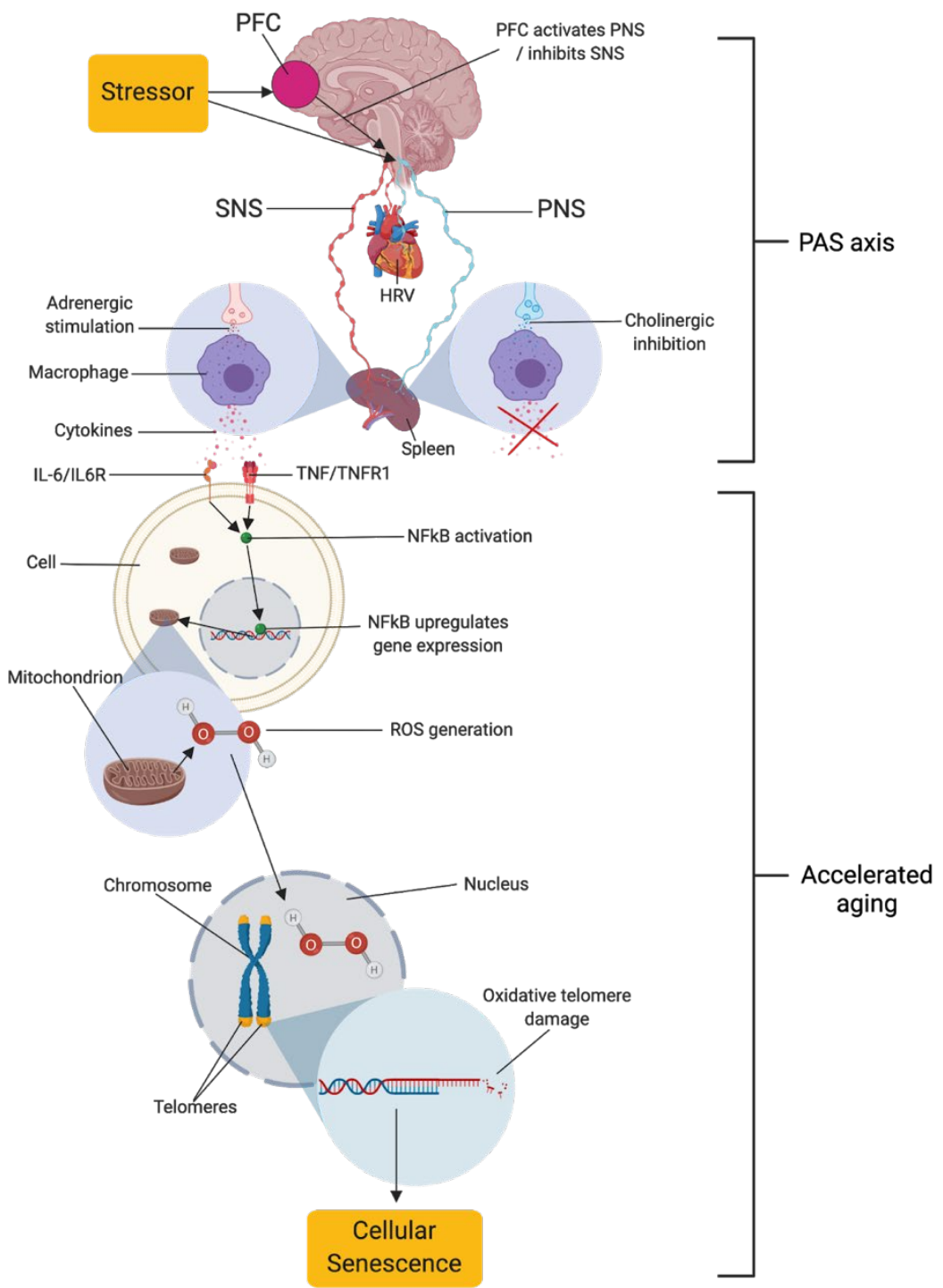

Figure 2 The neuro-immuno-senescence integrative model (NISIM). The NISIM propose that the link between psychological stress and telomere length starts with (1) prefrontal capacity for increasing activity in the vagus nerve, (2) vagal input to the spleen modulating the inflammatory response (3), subsequent inflammatory load increasing Nuclear Factor Kappa B (NFkB) activity and reactive oxygen species generation, and (4) the resulting oxidative damage to telomeres (Ask et al., 2018). PFC $=$ Prefrontal cortex. SNS = Sympathetic nervous system. PNS = Parasympathetic nervous system. HRV $=$ Heart rate variability. PAS axis $=$ Prefrontal cortexautonomic nervous system-spleen axis. IL-6 = Interleukin 6. IL6R = IL6 receptor. TNF = Tumor Necrosis Factor. TNFR1 $=$ TNF receptor 1. ROS $=$ Reactive oxygen species. $\mathrm{HOOH}=$ Hydrogen peroxide. Figure created with BioRender.com.

It is important to note that the mechanisms outlined by the NISIM are not suggested to be the main drivers of cellular senescence. The NISIM should rather be viewed as detailing the neuroimmunological mechanisms underlying individual differences in small but cumulative antecedents to cellular senescence that accelerate the transition from health to age-related pathology (Ask et al., 2018). Higher vmHRV has been linked to increased life-span (Piccirillo et al., 1998; Shimizu et al., 2002), while both lower vmHRV and proxies of low vmHRV predict all-cause mortality (Tsuji et al., 1994), cancer onset (Kennedy et al., 2017), Parkinson disease onset (Alonso et al., 2015), Alzheimer's disease onset (Wang et al., 2012), is associated with cognitive decline (Kim et al., 2007; Al Hazzouri et al., 2017), and degree of cognitive 
bioRxiv preprint doi: https://doi.org/10.1101/2022.02.17.480574; this version posted February 22, 2022. The copyright holder for this preprint (which was not certified by peer review) is the author/funder, who has granted bioRxiv a license to display the preprint in perpetuity. It is made available under aCC-BY-NC-ND 4.0 International license.

impairment in Alzheimer's (Santos et al., 2017; Zulli et al., 2006). The NISIM proposes that these relationships can in part be attributed to low or reduced prefrontal modulation of vagal activity resulting in inflammatory responses that accelerate cellular aging (Ask et al., 2018). Although numerous evidence converges on this interpretation, studies simultaneously assessing indicators of prefrontally mediated vagal tone, markers of inflammation, and their relationships with antecedents to cellular senescence has yet to be conducted. Analyzing these relationships are the current aim of the present study.

\subsection{The prefrontal cortex-autonomic nervous system-spleen (PAS) axis and its role in neuroimmunomodulation}

Senescent cells are adaptive in a young organism but can be detrimental to the health of older organisms in which they tend to accumulate (Campisi, 2000). The idea that the same biological function (e.g. the genes regulating cellular senescence) can produce two seemingly opposing phenotypes (health and disease) is called antagonistic pleiotropy (Williams, 1957). The evolutionary explanation for why cellular senescence protects young organisms but promotes age-related pathology in older organisms has been described elsewhere (e.g. Ask et al., 2018; Campisi, 2000). In short, the evolutionary account attributes the opposing phenotypes of healthy-young and sick-old to the fact that cellular senescence evolved as an adaptive response to cellular stress in organisms that had a much shorter life-span than humans have today. The same evolutionary principle can be attributed to inflammation. Psychological stress and arousal is associated with increased expression of inflammatory markers (Maydych, 2019). In the wild, organismal stress usually occurs when life is in danger and increased inflammatory expression prepares the organism to battle infections that might occur in wounds from fighting other organisms (Semple et al., 2002). As humans live longer due to improved standards of living, stress-induced inflammatory responses that protect the young organism from infection become a driver of age-related pathology in older organisms through induction of chronic low-grade inflammation (Liu et al., 2017).

Due to the capacity of the human brain to represent and solve problems cognitively while being physically and temporally removed from the source of the problem, humans can mentally represent and maintain psychological stressors through perseverative cognitions (Brosschot et al., 2005). Perseverative cognitions are associated with increased levels of inflammation (e.g. Moriarity et al., 2019). This inflammation-associated problem-solving ability might be helpful if it is in anticipation of an actual and imminent threat (e.g. a medical doctor knowing they are about to enter an environment with high levels of infection) by subtly boosting inflammation prior to exposure. If an individual is not capable of disengaging from perseverative thought in the absence of a stressful context, it can be a health risk by sustaining responses that contribute to the chronic low-grade inflammation associated with aging (Moriarity et al., 2019). Thus, psychological stress can contribute to inflammation in humans either as a result of direct exposure to the stressor or through the evolved ability for perseverative mental representation of stressors.

Stressors, and the resulting levels of arousal can induce inflammatory responses in several ways, one of which includes pathways via the autonomic nervous system (ANS) fibers descending into lymphoid tissues such as the spleen (Felten \& Felten, 1994; Rosas-Ballina et 
bioRxiv preprint doi: https://doi.org/10.1101/2022.02.17.480574; this version posted February 22, 2022. The copyright holder for this preprint (which was not certified by peer review) is the author/funder, who has granted bioRxiv a license to display the preprint in perpetuity. It is made available under aCC-BY-NC-ND 4.0 International license.

al., 2008). Sympathetic nerve fibers can induce inflammation by transmitting adrenergic ligands onto $\alpha$-subtype adrenoceptors on leukocytes in the spleen (Madden et al., 1995; Vizi, 1998) while vagal nerve fibers can suppress inflammation (Tracey 2002, 2007) through the transmission of cholinergic ligands onto the $\alpha 7$ nicotinic acetylcholine receptors on leukocytes (Huston et al., 2006; Wang $\mathrm{H}$ et al., 2003; Wang, 2004). The cholinergic modulation of inflammation is mediated by the splenic nerve (Rosas-Ballina et al., 2008). This makes the spleen a neuroimmune interface that allows the nervous system to adapt inflammatory responses to situational stressors (Noble et al., 2018; Rosas-Ballina et al., 2008).

Through its expansion, the prefrontal cortex (PFC) is arguably the most recently evolved structure in the human brain and is involved in executive functioning and in the adaptive regulation of the physiological, emotional, cognitive, and behavioral responses to acute and chronic stress (Appelhans \& Luecken, 2006; Gross et al., 1998). The PFC achieves this in part by modulating activity in the ANS through its connections with the amygdala and preautonomic cell groups in the hypothalamus, periaqueductal grey, and brainstem (Golkar et al., 2012; Seeley et al., 2007). To reduce arousal, the PFC can either increase activity in the vagus nerve or inhibit activity in the sympathetic nervous system. Higher prefrontal activity is reflected in higher vmHRV (Jennings et al., 2017; Nikolin et al., 2017; Thayer et al., 2012), an indicator of prefrontally modulated vagal tone, and higher vmHRV predicts better regulation of physiological arousal during prolonged stressors (Hildebrandt et al., 2016). Due to its ability to modulate ANS activity, the PFC is arguably a central component in adapting the ANSmodulated inflammatory response to situational needs. Consequently, lower prefrontal capacity for ANS modulation will result in inappropriate levels of inflammation in response to stress. Recent research showed that there was an inverse relationship between perseverative cognitions, PFC-associated executive functioning (e.g. Cropley \& Collins, 2020) and vmHRV (Cropley et al., 2017), linking PFC activity to inflammation. Further evidence for the relationship between PFC function and inflammation was confirmed in a meta-analysis linking the activity in several prefrontal structures with the peripheral expression of inflammatory markers (Kraynak et al. 2018). Together, the interplay between these anatomical components constitute a prefrontal cortex-autonomic nervous system-spleen (PAS) axis, suggesting that an individual's capacity for regulating stress responses through prefrontal modulation of vagus nerve activity has downstream effects on inflammation. To the best of our knowledge, this is the first paper conceptualizing these relationships as an axis.

The relationship between vagal tone and inflammatory markers has been reviewed in studies using healthy human participants (Ask et al., 2018) and participants with cardiovascular diseases (Haensel et al., 2008; Papaioannou et al., 2013). Although indicative of a relationship, evidence remained rather inconclusive. In a recent meta-analysis (Williams et al., 2019), the relationship between HRV and inflammatory marker-expression was revisited. The metaanalysis included data on several HRV indices and markers of inflammation, including IL-1, IL-2, IL-4, IL-6, and IL-10, CRP, leukocyte (white blood cell; WBC) count, Fibrinogen, Interferon-gamma (IFN- $\gamma$ ) and TNF- $\alpha$. The high-frequency component of HRV (HFHRV) showed the strongest association to inflammatory markers of all vmHRV indices, with CRP and IL-6 showing the most reliable relationships with HFHRV (Williams et al., 2019). No significant associations were found between time domain measures of vmHRV (the Root Means Square of Successive Differences; RMSSD) and IL-6. An explanation for this 
bioRxiv preprint doi: https://doi.org/10.1101/2022.02.17.480574; this version posted February 22, 2022. The copyright holder for this preprint (which was not certified by peer review) is the author/funder, who has granted bioRxiv a license to display the preprint in perpetuity. It is made available under aCC-BY-NC-ND 4.0 International license.

discrepancy may be attributed to that RMSSD might be influenced by sympathetic activation (Berntson et al., 2005). Vagal (Huston et al., 2006; Wang H et al., 2003) and sympathetic (Madden et al., 1995; Vizi et al., 1998) inputs to the spleen have opposing effects on inflammatory marker expression. Moreover, IL-6 appears to have a stronger relationship with HFHRV than CRP (Williams et al., 2019), possibly due to CRP expression being downstream of IL-6 expression (Boras et al., 2014) as it is mainly synthesized through IL-6-dependent hepatic biosynthesis (Baumeister et al., 2016; Pradhan et al., 2001). No significant associations were found between TNF- $\alpha$ and vmHRV, although the authors note that the sample sizes for studies assessing these relationships were small (Williams et al., 2019). The authors concluded that there was evidence for a vagal modulation of inflammation in humans, providing statistical support for a PAS axis. The NISIM argues that the PAS axis is the common denominator in both how individual differences in stress regulation capacity translates to inflammation-related pathology as well as explaining why they are subtle and accumulate over time (Ask et al., 2018).

\subsection{PAS axis dysregulation and implications for the NISIM}

The NISIM suggests that a dysregulated PAS axis will result in increased inflammation-induced levels of reactive oxygen species (ROS), which in turn will accelerate ROS-induced telomere shortening resulting in cellular senescence (Ask et al., 2018). Telomeres are DNA-protein complexes consisting of base pairs of TTAGGG repeats that cap the ends of linear chromosomes to protect them from end-to-end fusion by DNA-repair processes and degradation (Blackburn, 1991; Verdun \& Karlseder, 2006). When telomeres become dysfunctional, either through oxidative DNA damage or mitosis-associated telomere attrition, the DDR response is activated and if persisting will result in cellular senescence (Campisi, 2013; Coluzzi et al., 2019). Shorter telomeres have been reported to increase risk for Alzheimer's (Thomas et al., 2008). Whether shorter telomeres are a risk for cancer development might depend on cancer type (Zhu et al., 2016), although telomere dysfunction can occur irrespective of telomere length (Victorelli \& Passos, 2017). An increasing number of studies link inflammation to telomere length. A two-year longitudinal study found negative associations between CRP and telomere length (Wong et al., 2014) and genetically elevated CRP levels were found to be inversely associated with telomere length (Rode et al., 2014). Interestingly, an inverse relationship between CRP levels and telomere length was found among depressed young men, suggesting a relationship between emotion dysregulation and telomere attrition (Shin et al., 2019). Similarly, inverse relationships have also been found between telomere length and vmHRV (Perseguini et al., 2015; Streltsova et al., 2017; Woody et al., 2017; Zalli et al., 2013; but see also Epel et al., 2006).

While these data indicate that a dysregulated PAS axis contributes to the antecedents to cellular senescence, more direct measures of PAS axis activity with respect to telomere length are lacking. One method of approximating this problem would be to assess inflammation as a mediator in the relationship between vagal tone and telomere length.

\subsection{The neuroimmunomodulation (NIM) index as an indicator of PAS axis activity}


It is known that distressful psychological states associated with emotional dysregulation and lower PFC activity such as depression and loneliness are related to cancer progression and survival (Pinquart \& Duberstein, 2010; Rico-Uribe et al., 2018). A series of studies associating vagal tone with cancer survival provided some of the first evidence suggesting that the ability of the PFC to modulate vagal activity and the resulting modulation of the immune system could be a manner of life and death in clinical conditions (Chiang et al., 2013; De Couck et al., 2013; Mouton et al., 2010, 2011, 2012). As vmHRV alone does not predict all outcomes (Gidron et al., 2005, 2018), and because it was found that CRP statistically mediates the relationship between vmHRV and survival in patients with pancreatic cancer (De Couck et al., 2015), there has been a need for a biomarker that can serve as a proxy relating vagal activity to modulation of the immune response. In absence of an index for this relationship, Gidron et al. (2018) proposed the neuroimmunomodulation (NIM) index; a simple numerical ratio (vmHRV/CRP) indexing vagal immunomodulation of inflammation. They found that the NIM index had a protective relative risk among pancreatic and non-small cell lung cancer patients and that nonsmall cell lung cancer patients with higher NIM index survived longer than those with lower NIM index scores. The authors suggested that this novel index could serve as an independent prognostic biomarker for cancer (Gidron et al., 2018). Inflammatory markers do not necessarily reflect vagal activity, nor does vagal activity necessarily reflect inflammation. Thus, the NIM index could potentially be a more sensitive measure of PAS axis activity than any of the measures in isolation. How NIM index scores, and by extent PAS axis activity, relate to antecedents of cellular senescence such as telomere length has yet to be explored.

\subsection{Aim}

The NISIM (Ask et al., 2018) proposes that for psychological effects on telomere length, prefrontal cortical influences on the vagus nerve modulate the inflammatory response with reduced telomere length being downstream of inflammation. Thus, the main aim of this paper is to test the hypothesis that inflammation negatively mediates the relationship between vagal tone and telomere length. The secondary aim is to assess whether the NIM index (Gidron et al., 2018) could serve as a useful index for the PAS axis in the NISIM by assessing whether the NIM index is a positive predictor of telomere length, and assess its sensitivity by comparing it to the mediation analysis. Due to the scarcity of existing data, the tertiary aim of this study is to replicate previous findings relating vagal tone to telomere length.

\section{$2 \quad$ Methods}

\subsection{Ethics statement}

This study uses participant data from the sixth survey of the Tromsø Study (Tromsø6; Eggen et al., 2013) which was collected from 2007 to 2008. Seven surveys have been carried out so far. Tromsø6 was approved by the Data Inspectorate of Norway and the Regional Committee of Medical and Health Research Ethics, North Norway. Tromsø6 complies with the Declaration of Helsinki, International Ethical Guidelines for Biomedical Research Involving Human Subjects and the International Guidelines for Ethical Review of Epidemiological Studies. 
bioRxiv preprint doi: https://doi.org/10.1101/2022.02 17.480574: this version posted February 22,2022 . The copyright holder for this preprint (which was not certified by peer review) is the author/funder, who has granted bioRxiv a license to display the preprint in perpetuity. It is made available under aCC-BY-NC-ND 4.0 International license.

Participation was voluntary and each subject gave written informed consent prior to participation.

\subsection{Participants}

The Tromsø Study cohort consists of people living in the municipality of Tromsø, Norway, situated at $69^{\circ}$ North. Among the 70,000 people living in Tromsø when Tromsø6 was carried out, approximately 60,000 were living in the city-like town-center, while the remaining 10,000 were spread throughout the whole municipality $\left(2558 \mathrm{~km}^{2}\right)$. Troms $\varnothing$ is a center of education, research, administration and fishing related activities. It has a growing population that is predominantly Caucasians of Norwegian origin, but also includes a Sami minority. Tromsø may be considered as representative of a Northern European, white, urban population. A total of 12984 (male $=6054$ ) participants aged 30-87 years $(\mathrm{M}=57.5, \mathrm{SD}=12.7)$ enrolled in Tromsø6. Of these, 9946 participated in a cold-pressor test (described in Schistad et al., 2017) where blood pressure (BP) was measured for inter-beat-interval (IBI) extraction and vmHRV quantification. A total of 1372 participants from whom both telomere length and vmHRV measures could be obtained was included in the analysis. Characteristics of the study sample can be found in Table 1.

Table 1 Study sample characteristics $(N=1372)$

\begin{tabular}{|c|c|c|c|c|}
\hline Characteristics & Number & Prevalence $(\%)$ & Mean & SD \\
\hline $\mathrm{Age}^{1}$ & & & 57.5 & 12.7 \\
\hline Male $^{1}$ & 6054 & 46.6 & & \\
\hline \multicolumn{5}{|l|}{ Mental health } \\
\hline Felt depressed during last week & 226 & 16.5 & & \\
\hline Felt useless or worthless during last week & 183 & 13.3 & & \\
\hline Felt hopelessness during last week & 197 & 14.4 & & \\
\hline \multicolumn{5}{|l|}{ Sleeping problems } \\
\hline $\begin{array}{l}\text { Sleeplessness }>\text { once per week during last } \\
12 \text { months }\end{array}$ & 183 & 13.3 & & \\
\hline Sleeping problem during last week & 512 & 37.3 & & \\
\hline \multicolumn{5}{|l|}{ Alcohol and tobacco use } \\
\hline Alcohol use $>2$ days per week & 280 & 20.4 & & \\
\hline Usual alcohol units $>1-2$ & 313 & 22.8 & & \\
\hline 6 alcohol units or more $\geq$ once per week & 26 & 1.9 & & \\
\hline Daily smoking & 218 & 15.9 & & \\
\hline Used to smoke daily & 701 & 51.1 & & \\
\hline Cigarettes per day & & & 11.9 & 8.9 \\
\hline Years of daily smoking & & & 30.3 & 15.7 \\
\hline Years of daily smoking $>1$ year $^{2}$ & 852 & 99.5 & & \\
\hline Age when started smoking (years) & & & 19.6 & 5.9 \\
\hline Years since smoking cessation & & & 22.9 & 14.6 \\
\hline Use snus/snuff/chewing tobacco & 41 & 3 & & \\
\hline Previous snus/snuff/chewing tobacco use & 15 & 1.1 & & \\
\hline
\end{tabular}




\subsection{Vagally mediated heart rate variability (vmHRV)}

\subsubsection{Recording, data reduction and analysis}

BP was measured noninvasively for 30 seconds using a finometer device (Finometer, Finapres Medical System, Amsterdam, Netherlands) where the sensor was placed on the participant's finger. The original dataset consisted of 9946 recordings of IBI over a mean duration of 310 samples from which heart periods were extracted, artifacts were corrected and time-domain and frequency-domain HRV parameters were derived. For pre-processing, artifact correction, and data formatting, Matlab R2015 (MATLAB, 2015) was used. For the calculation of all timedomain and frequency-domain HRV parameters, the RHRV package (Martínez et al., 2017) in the $\mathrm{R}$ language (R Core Team, 2020) was employed.

\subsubsection{Artifact correction}

Artifacts was removed using a distribution-based algorithm that identifies artifacts as statistical outliers within a moving window and replaces them by linear interpolation (Deegan et al., 2007a, 2007b). The total distribution of IBI values (after the artifact correction) from all subjects was inspected in a histogram which revealed a small portion of values outside of the physiological range (i.e. IBI $>3 \mathrm{~s}$ ). A low and high cut-off limit for IBI observations of physiological origin was set to $0.3 \mathrm{~s}$ and $2.5 \mathrm{~s}$, respectively. All recordings having at least one observation outside this limit were omitted $(n=378 ; 3.8 \%$ of the total of 9946$)$.

\subsubsection{Calculation of HRV parameters in RHRV}

Data files of the IBI for each recording were generated using a Matlab script then loaded into the RHRV script for HRV calculation. RHRV includes artifact removal by eliminating outliers or spurious points in the time-series with unacceptable physiological values. This method was compared to the Deegan et al. (2007a, 2007b) method by calculating all time-domain and frequency-domain parameters using both the raw and corrected (Deegan et al., 2007a, 2007b) IBI data. There was a significant disagreement between the two. Thus, the artifact-corrected data were used as input for the HRV calculations in RHRV.

\subsubsection{Time domain parameters}

Due to the short data length of our recordings (30s), the triangular interpolation of $\mathrm{NN}$ histogram and HRV index parameters was calculated using the shape of the histogram of the RR intervals. To assess how bin width selection affected recordings, histograms of the default (8ms), lower (4ms) and higher (12ms) bin widths were compared for 25 random recordings. Plotted on top of each other, the $4 \mathrm{~ms}$ bin gave a too sharp shape, while the $12 \mathrm{~ms}$ bin width gave a too blurry representation of the shape. Thus, the default setting of $7.8125 \mathrm{~ms}$ was used.

\subsubsection{Frequency domain parameters}

For calculation of the frequency-domain parameters, Fourier-based signal power calculation in the LF, MF and HF bands were used. The whole recording duration is used as the window size in this calculation, thus there is no other setting for the Fourier method. The signal power was 
bioRxiv preprint doi: https://doi.org/10.1101/2022.02.17.480574; this version posted February 22, 2022. The copyright holder for this preprint (which was not certified by peer review) is the author/funder, who has granted bioRxiv a license to display the preprint in perpetuity. It is made available under aCC-BY-NC-ND 4.0 International license.

calculated in three bands (Task Force, 1996): LF (0.04-0.15 Hz), MF (0.07-0.15 Hz) and HF (0.15-0.4 Hz).

\subsubsection{Identification of outlier cases}

All measurements where the Standard Deviation of NN/(RR) intervals $\geq 150$ were visually inspected $(\mathrm{n}=107) .13$ of the identified measurements were suspected of measurement error (e.g. due to displaying doubling and then halving of IBI length). These were noted so that they could be excluded from the analysis.

\subsection{8 vmHRV indices of interest}

Two commonly used indicators of vagal tone are the time domain measure RMSSD and the high-frequency component measure HFHRV (Task Force, 1996; Thayer et al., 2012). We were mainly interested in HFHRV due to RMSSD possibly being influenced by sympathetic activation (Berntson et al., 2005) and vagal (Huston et al., 2006; Wang H et al., 2003) and sympathetic (Madden et al., 1995; Vizi et al., 1998) inputs to the spleen having opposing effects on inflammatory marker expression. RMSSD and HFHRV are usually highly correlated (Goedhart et al., 2007). Due to the short data length of our recordings, RMSSD was included in the analysis to check for this correlation to assure that vmHRV indices were of good quality.

\subsection{Reactive Protein (CRP), Leukocyte (WBC) count, and Leukocyte telomere length (LTL) quantification}

Blood sampling is described in Eggen et al. (2013). The participants were not required to fast, but they were only allowed to drink water and black coffee during their visits. $50 \mathrm{ml}$ blood samples were collected $(\mathrm{n}=12,882)$. Time since last meal (hours) was recorded. Venipuncture was performed with subjects in a sitting position. A light tourniquet was used and released before sampling. After 30 minutes at room temperature, the coagulated samples were centrifuged at $2000 \mathrm{~g}$ for 10 minutes, and the sera were transferred within 1 hour to plastic tubes, and kept between $1{ }^{\circ} \mathrm{C}$ and $10^{\circ} \mathrm{C}$. The blood samples were sent twice daily to the Department of Laboratory Medicine, University Hospital North Norway, Tromsø, which is an accredited laboratory (ISOstandard 17025).

CRP was analyzed by a highly sensitive CRP method (particle-enhanced immunoturbidimetric assay). The analyses were performed on a Modal PPE auto-analyzer with reagents from Roche Diagnostics Norway AS.

For WBC, $5 \mathrm{ml}$ of blood was collected into Vacutainer tubes containing EDTA as an anticoagulant (K3-EDTA 40 11, $0.37 \mathrm{~mol} / \mathrm{l}$ per tube), and analyzed within $12 \mathrm{hr}$ by an automated blood cell counter (Coulter CounterÒ, Coulter Electronics, Luton, UK and Coulter LH750, Nerliens Meszansky). Leukocyte telomere length (LTL) was analyzed by established qPCR methods (O'Callaghan \& Fenech, 2011) at McGill University in 2018 and the mean telomere length was quantified as arbitrary units.

\subsection{Vagal immunomodulation index}


bioRxiv preprint doi: https://doi.org/10.1101/2022.02.17.480574; this version posted February 22, 2022. The copyright holder for this preprint (which was not certified by peer review) is the author/funder, who has granted bioRxiv a license to display the preprint in perpetuity. It is made available under aCC-BY-NC-ND 4.0 International license.

To calculate the neuroimmunomodulation (NIM) index, the high frequency component of HRV (HFHRV) was divided by participants' CRP to obtain the HFHRV/CRP ratio in accordance with Gidron et al. (2018).

\subsection{Confounding variables}

One major issue facing the literature on associations between vmHRV and inflammatory markers is the lack of controlling for confounding variables (Haensel et al., 2008; Papaioannou et al., 2013). Timing from last meal to blood samples being drawn (Marinac et al., 2015), disturbed sleep (Irwin et al., 2018), depression (Lee et al., 2019), and alcohol and tobacco use (e.g. Tibuakuu et al., 2017; van de Loo et al., 2020) are all associated with inflammatory marker expression as well as PFC activity and vmHRV. Thus, measures assessing these variables were included as control variables in the analysis.

WBC has previously been found to be positively associated with LTL (Neuner et al., 2015) and telomere length varies between different subtypes of leukocytes (Rufer et al., 1998; Wong et al., 2011). Considering the positive associations between WBC and CRP (Sproston \& Ashworth, 2018), and negative associations between CRP and LTL (Rode et al., 2014; Wong et al., 2014), WBC could serve as a positive confounder in the relationship between CRP and LTL. It could also serve as a confounder in the relationship between the vagal tone and LTL, as vagal and sympathetic activity differentially regulate leukocyte activity with vmHRV being negatively associated with WBC (Williams et al., 2019). WBC was therefore included as a control variable in the analysis.

\subsection{Statistical analysis}

First, visual inspection of the variables revealed that LTL, WBC, CRP, NIM index, and HRV were not normally distributed. $\log 10$ transformation was performed on these variables prior to analysis. After $\log 10$ transformation, visual inspection confirmed normal distribution. All subsequent analyses were performed on the $\log 10$ transformed version of these variables.

Pearson correlations were conducted for HFHRV, RMSSD, LTL, the NIM index, CRP, and $\mathrm{WBC}$ to assess the relationship between the variables.

All regression analyses were checked for violation of assumptions regarding normality, linearity, and homoscedasticity by plotting standardized predicted values against standardized residuals, and multicollinearity was assessed by checking that variance inflation factor values $\approx 1$. No assumptions were violated at any time. Mediation analyses were performed using a series of hierarchical multiple linear regression (two models per analysis). Due to a positive correlation between WBC and LTL, and WBC and CRP in our sample, WBC was used as a control variable in all regression analyses. In the first model of the first analysis, LTL was entered as the dependent variable and compared against the control variable, WBC, which was entered as an independent variable. Then, in the second model of the first analysis, HFHRV was entered as the independent variable and compared against the dependent variable to examine main effects of the HFHRV on the LTL (path C). In the first model of the second analysis, CRP was entered as the dependent variable with WBC as independent variable. In the second model of the second analysis, HFHRV was entered as the independent variable and 
bioRxiv preprint doi: https://doi.org/10.1101/2022.02.17.480574; this version posted February 22, 2022. The copyright holder for this preprint (which was not certified by peer review) is the author/funder, who has granted bioRxiv a license to display the preprint in perpetuity. It is made available under aCC-BY-NC-ND 4.0 International license.

compared against the dependent variable to examine main effects of the HFHRV on the CRP (path A). In the first model of the third analysis LTL was entered as the dependent variable and compared against the control variable, WBC, which was entered as an independent variable. Finally, in the second model of the third analysis, HFHRV and CRP were both entered as independent variables and compared against the dependent variable (LTL) to examine main effects of CRP on LTL (Path B) and HFHRV on the LTL (path C') simultaneously. To calculate the total effect of path A and B on LTL, path A was multiplied with path B (A*B).

Multiple linear regression analysis was performed on the NIM index and LTL (NIMLTL model). WBC was entered as the independent (control) variable and LTL as the dependent variable in model 1, and the NIM index and WBC as the independent variables and LTL as the dependent variable in model 2. When controlling for confounders, hierarchical multiple linear regression was used following the same steps as in the initial regression analysis. All control variables were individually entered as predictor variables in model 1 along with WBC, and with LTL as outcome variable. In the next step (model 2), HFHRV and CRP were entered simultaneously as predictor variables. This was repeated for all control variables. Regression analyses were also performed without WBC as a control variable to assess how its inclusion affected results. Control variables were either continuous or numerical.

Additional regression analyses were performed with a reduced dataset $(n=169)$ excluding all participants that reported sleeping problems once per week or more during the past 12 months, symptoms of depression (feeling depressed, feeling worthless or useless, feeling hopelessness for the future), current or previous history of smoking or smokeless tobacco use, drinking more than 2-4 times per month, usually consuming more than four units of alcohol when drinking. This was done for both the mediation analysis and NIM index analysis while controlling for WBC. Descriptive statistics were generated for the reduced dataset. After exclusion of 13 outlier cases suspected of measurement error, regression analyses were repeated on the original $(n=1359)$ and reduced $(n=165)$ dataset.

Data was analyzed using SPSS version 25 (IBM Corp, 2017).

\section{$2 \quad$ Results}

\subsection{Participant characteristics and descriptive statistics of vmHRV, NIM index, and biomarkers}

The demographic characteristics of the studied population $(\mathrm{N}=1372)$ are shown in Table 1. With respect to confounders of vmHRV, PFC, and inflammatory marker expression, 226 participants reported feeling depressed, 183 reported feeling useless or worthless, and 197 reported feeling hopelessness during the past week. 183 participants reported having sleeping problems more than once per week during the last 12 months. 280 participants reported alcohol use more than two days per week, 313 participants reported drinking more than 2 units of alcohol when drinking, while 26 participants reported drinking six or more units of alcohol once or more per week. 218 participants were daily smokers while 701 participants used to be daily smokers. 41 participants reported current use of snus/snuff/chewing tobacco. Table 2 provides descriptive statistics for extracted vmHRV and NIM indices, LTL, CRP, and WBC before and after $\log 10$ transformation, and time since last meal (hours). 
bioRxiv preprint doi: https://doi org/10.1101/2022.02 17.480574; this version posted February 22,2022 . The copyright holder for this preprint (which was not certified by peer review) is the author/funder, who has granted bioRxiv a license to display the preprint in perpetuity. It is made available under aCC-BY-NC-ND 4.0 International license.

Table 2 Descriptive statistics for vmHRV and NIM indices, Telomere length, CRP, Leukocyte count, and Time since last meal

\begin{tabular}{lccccc}
\hline Variable & Mean & Std. & Minimum & Maximum & N \\
\hline RMSSD & 32.98 & 40.38 & 4 & 563 & 1372 \\
RMSSD_log10 & 1.36 & .32 & .56 & 2.75 & 1372 \\
HFHRV & 300.37 & 1579.79 & 1 & 48970 & 1372 \\
HFHRV_log10 & 1.78 & .65 & -.11 & 4.69 & 1372 \\
NIM & 213.52 & 815.56 & .04 & 19203.73 & 1371 \\
NIM_log10 & 1.56 & .80 & -1.41 & 4.28 & 1371 \\
LTL & 1.31 & .57 & 0 & 5 & 1372 \\
LTL_log10 & .08 & .18 & -.62 & .69 & 1372 \\
CRP & 2.99 & 5.57 & 0 & 81 & 1371 \\
CRP_log10 & .22 & .42 & -.72 & 1.91 & 1371 \\
WBC & 6.3 & 2.07 & .11 & 39 & 1369 \\
WBC_log10 & .78 & 1.77 & 0 & 1.59 & 1369 \\
Time since last meal & 3.36 & .04 & 9 & 1364 \\
\hline Notes. RMSSD & Rot & .11 & 0 & 5
\end{tabular}

Notes. RMSSD $=$ Root mean square of successive differences. _log10 = Log10 transformed variable. HFHRV $=$ High frequency component heart rate variability. NIM $=$ Neuroimmunomodulation index. LTL $=$ Leukocyte telomere length arbitrary units. $\mathrm{CRP}=\mathrm{C}$-Reactive Protein. $\mathrm{WBC}=$ Leukocyte count.

\subsection{Relationship between vmHRV, CRP, and LTL}

RMSSD and HFHRV were highly correlated $(r=.904, \mathrm{p}<.001)$. Table 3 provides correlation between vmHRV indices, LTL, CRP, NIM index, and WBC. HFHRV was significantly associated with LTL $(r=.068, p=.012)$ and CRP $(r=-.068, p=.012)$. HFHRV was not significantly associated with WBC. The NIM index was significantly associated with LTL $(r=$ $.067, \mathrm{p}=.013)$, CRP $(\mathrm{r}=-.579, \mathrm{p}<.001)$, and WBC $(\mathrm{r}=-.113, \mathrm{p}<.001)$. CRP was not significantly associated with LTL. CRP was significantly associated with WBC $(\mathrm{r}=.286, \mathrm{p}<$ $.001)$. WBC was significantly associated with LTL $(\mathrm{r}=.164, \mathrm{p}<.001)$. Time since last meal was positively associated with LTL $(r=.067, \mathrm{p}=.014)$.

Table 3 Pearson correlations (r) between vmHRV, LTL, CRP, NIM, and WBC $(N=1372)$

\begin{tabular}{llllllll}
\hline Variables & $\mathbf{1}$ & $\mathbf{2}$ & $\mathbf{3}$ & $\mathbf{4}$ & $\mathbf{5}$ & $\mathbf{6}$ & $\mathbf{7}$ \\
\hline $\mathbf{1}$ HFHRV & - & & & & & & \\
$\mathbf{2}$ RMSSD & $.904 * * *$ & - & & & & \\
$\mathbf{3}$ NIM & $.853 * * *$ & $.760^{* * *}$ & - & & & \\
$\mathbf{4}$ LTL & $.068^{*}$ & .047 & $.067 *$ & - & & \\
$\mathbf{5}$ CRP & $-.068^{*}$ & -.040 & $-.579 * * *$ & -.018 & - & \\
$\mathbf{6}$ WBC & .035 & .017 & $-.113^{* * *}$ & $.164 * * *$ & $.286^{* * *}$ & - & \\
$\mathbf{7}$ TSLM & .025 & $.054 *$ & .014 & $.067 *$ & .014 & .039 & - \\
\hline
\end{tabular}

Notes. 2-tailed. All variables are $\log 10$ transformed. HFHRV $=$ High frequency heart rate variability. RMSSD $=$ Root means squared of successive differences. NIM $=$ Neuroimmunomodulation index. LTL $=$ Leukocyte telomere length arbitrary units. $\mathrm{CRP}=\mathrm{C}$ reactive protein. $\mathrm{WBC}=$ Leukocyte count. $\mathrm{TSLM}=$ Time since last meal. $* \mathrm{p}<.05 . * * \mathrm{p}<.01 . * * \mathrm{p}<.001$ 
Table 4 provides the results for the hierarchical regression model with HFHRV and CRP as predictor variables and LTL as outcome variable. In the first regression analysis, HFHRV was a significant positive predictor of LTL $\left(\beta=.062, \mathrm{p}=.020, R^{2}{ }_{a d j}=.026, F=19.33\right)$ when controlling for WBC. In the second regression analysis, HFHRV was a significant negative predictor of CRP $\left(\beta=-.077, \mathrm{p}=.003, R^{2}{ }_{a d j}=.079, F=59.42\right)$ when controlling for WBC. In the third regression analysis, HFHRV was a significant positive predictor of LTL, and CRP was a significant negative predictor of LTL (HFHRV: $\beta=.057, p=.033$; CRP: $\beta=-.065, p=.020$; $\left.R^{2}{ }_{a d j}=.029 ; F=14.74\right)$ when controlling for WBC. The model with and without mediator is illustrated in Figure 3. CRP stopped being a significant predictor of LTL when not controlling for WBC.

Table 4 Multiple linear regression analysis for HFHRV, CRP, and LTL $(N=1372)$

\begin{tabular}{lccc}
\hline & \multicolumn{3}{c}{ LTL } \\
\cline { 2 - 4 } Predictors (model 1) & $\boldsymbol{\beta}$ & $\boldsymbol{R}^{2}{ }_{\text {adj }}$ & Sig. \\
\hline WBC & .154 & .023 & .000 \\
Predictors (model 2) & & & \\
WBC & .152 & .026 & .000 \\
HFHRV & .062 & .026 & .020 \\
\hline & & $\mathbf{C R P}$ & Sig. \\
Predictors (model 1) & $\boldsymbol{\beta}$ & $\boldsymbol{R}^{2}$ adj & .000 \\
\hline WBC & .272 & .074 & \\
Predictors (model 2) & & & .000 \\
WBC & .275 & .079 & .003 \\
HFHRV & -.077 & .079 & \\
\hline
\end{tabular}

LTL

\begin{tabular}{lccc}
\cline { 2 - 4 } Predictors (model 1) & $\boldsymbol{\beta}$ & $\boldsymbol{R}^{2}$ adj & Sig. \\
\hline WBC & .154 & .023 & .000 \\
Predictors (model 2) & & & \\
WBC & .170 & .029 & .000 \\
HFHRV & .057 & .029 & .033 \\
CRP & -.065 & .029 & .020 \\
\hline
\end{tabular}

Notes. All variables are $\log 10$ transformed. All analyses controlled for leukocyte count. WBC = Leukocyte count. $\mathrm{LTL}=$ Leukocyte telomere length arbitrary units. HFHRV $=$ High frequency heart rate variability. $\mathrm{CRP}=\mathrm{C}$ reactive protein. 

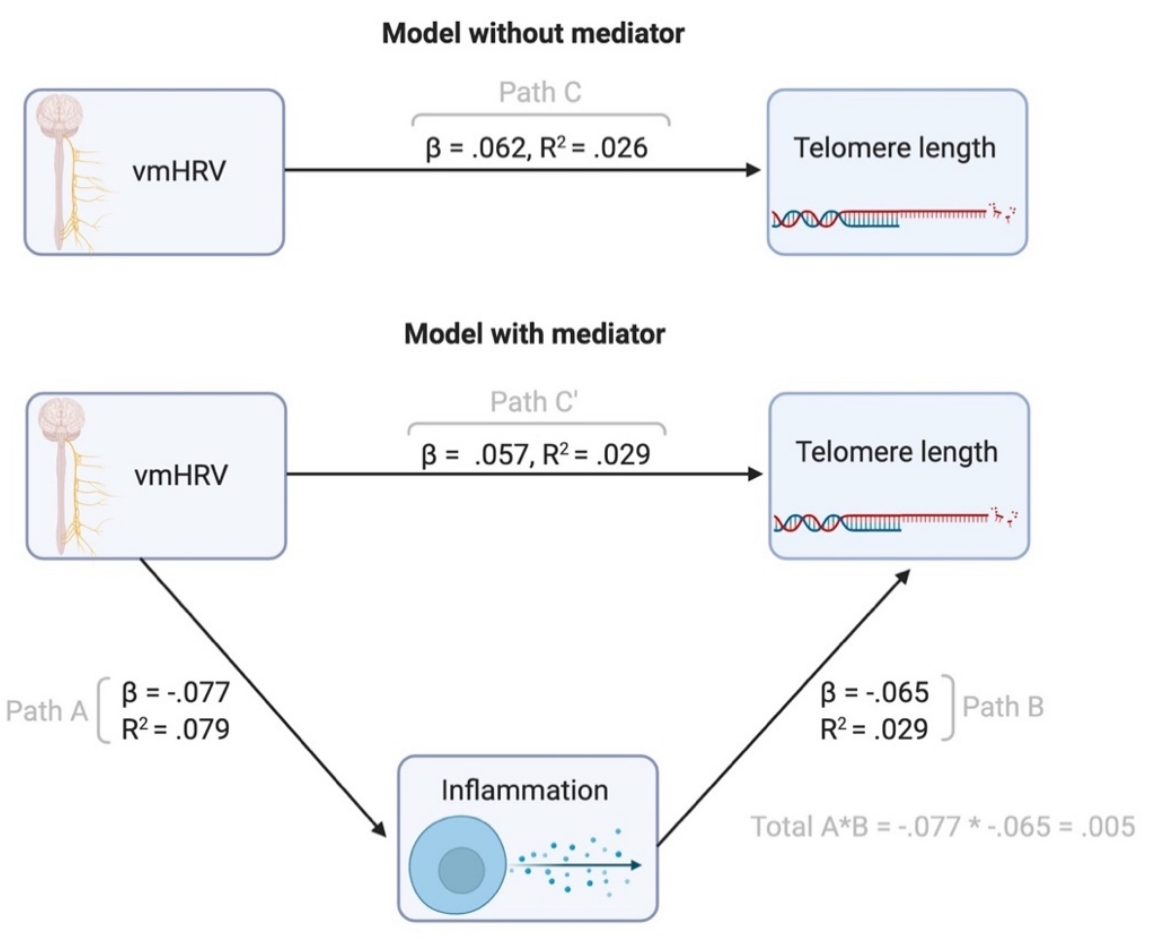

Figure 3 | Regression model with and without mediator. All relationships controlling for leukocyte count. Figure created with BioRender.com.

In the mediation model, all relationships remained significant when individually controlling for: time since last meal (HFHRV: $\beta=.056, p=.035$; CRP: $\beta=-.066, p=.017$; $R^{2}{ }_{a d j}=.032, F=12.21$ ), sleeplessness during the last 12 months (HFHRV: $\beta=.054, \mathrm{p}=.048$; CRP: $\beta=-.067, \mathrm{p}=.019 ; R^{2}$ adj $=.030, F=11.13$ ), frequency of alcohol consumption (HFHRV: $\beta=.054, \mathrm{p}=.045$; CRP: $\left.\beta=-.067, \mathrm{p}=.018 ; R^{2}{ }_{a d j}=.028, F=10.78\right)$, and how often participants drink 6 units of alcohol or more on one occasion (HFHRV: $\beta=.059, p=.038$; CRP: $\beta=-.057$, $\mathrm{p}=.050 ; R^{2}$ adj $\left.=.031, F=10.78\right)$.

HFHRV did not remain a significant predictor of LTL when individually controlling for: sleeping problems during last week, feeling depressed during last week, feeling worthless or useless during last week, feeling hopelessness during last week, units of alcohol consumed when drinking, previous or current daily smoking, and age when smokers started smoking daily. CRP did not remain a significant predictor of LTL when independently controlled for: occasional smoking, years since smoking cessation, snuff/chewing tobacco use. Neither HFHRV nor CRP remained significant predictors of LTL when independently controlling for: number of cigarettes smoked per day, years of smoking.

After exclusion of 13 outlier cases $(n=1359)$ suspected of IBI measurement error (as described in section 2.3.7) when simultaneously assessing the effect of HFHRV and CRP on LTL, CRP but not HFHRV (CRP: $\beta=-.066, \mathrm{p}=.018 ;$ HFHRV: $\beta=.052, \mathrm{p}=.053 ; R^{2}{ }_{\text {adj }}=.030$, $F=15.04$ ) remained a significant predictor of LTL when controlling for WBC.

\subsection{Relationship between the NIM index and LTL}


Table 5 provides the results for the hierarchical regression model with the NIM index as predictor variable and LTL as outcome variable. The NIM index was a significant positive predictor of LTL $\left(\beta=.085, \mathrm{p}=.001, R^{2} a d j=.030, F=21.77\right)$ when controlling for WBC.

Table 5 Regression analysis for the NIM index and LTL $(N=1372)$

\begin{tabular}{lccc}
\hline & \multicolumn{3}{c}{ LTL } \\
\cline { 2 - 4 } Predictors (model 1) & $\boldsymbol{\beta}$ & $\boldsymbol{R}^{2}{ }_{\text {adj }}$ & Sig. \\
\hline WBC & .154 & .023 & .000 \\
Predictors (model 2) & & & .000 \\
WBC & .164 & .030 & .001 \\
NIM & .085 & .030 & \\
\hline
\end{tabular}

Notes. All variables are $\log 10$ transformed. All analyses controlled for leukocyte count. NIM = Neuroimmunomodulation index. $\mathrm{WBC}=$ Leukocyte count. $\mathrm{LTL}=$ Leukocyte telomere length, arbitrary units.

In the NIM-LTL regression model, the NIM index remained a significant predictor of LTL when individually controlling for: time since last meal $\left(\beta=.086, \mathrm{p}=.001, R^{2}{ }_{\text {adj }}=.032, F\right.$ $=16.02)$, sleeplessness during the last 12 months $\left(\beta=.084, \mathrm{p}=.002, R^{2}{ }_{a d j}=.030, F=14.58\right)$, sleeping problems during last week $\left(\beta=.082, \mathrm{p}=.003, R^{2}\right.$ adj $\left.=.031, F=14.81\right)$, feeling depressed during last week $\left(\beta=.087, \mathrm{p}=.002, R^{2} a d j=.033, F=15.40\right)$, feeling worthless or useless during last week $\left(\beta=.086, \mathrm{p}=.002, R^{2}\right.$ adj $\left.=.031, F=14.34\right)$, feeling hopelessness during last week $\left(\beta=.087, \mathrm{p}=.002, R^{2}{ }_{a d j}=.032, F=15.07\right)$, frequency of alcohol consumption $\left(\beta=.084, \mathrm{p}=.002, R^{2}\right.$ adj $\left.=.028, F=14.09\right)$, units of alcohol consumed when drinking $(\beta=$ $.078, \mathrm{p}=.009, R^{2}$ adj $\left.=.028, F=11.73\right)$, how often participants drink 6 units of alcohol or more on one occasion $\left(\beta=.083, \mathrm{p}=.003, R_{a d j}^{2}=.032, F=14.36\right)$, occasional smoking $(\beta=.084$, $\mathrm{p}=.003, R^{2}$ adj $\left.=.037, F=16.32\right)$, previous or current daily smoking $\left(\beta=.079, \mathrm{p}=.003, R^{2}{ }_{a d j}=\right.$ $.036, F=17.87)$, years since smoking cessation $\left(\beta=.118, \mathrm{p}=.002, R^{2}{ }_{\text {adj }}=.028, F=7.78\right)$, cigarettes per day $\left(\beta=.081, \mathrm{p}=.025, R_{a d j}^{2}=.022, F=6.65\right)$, age when smokers started smoking daily $\left(\beta=.088, \mathrm{p}=.009, R^{2}\right.$ adj $\left.=.023, F=8.09\right)$, use of snuff or chewing tobacco $(\beta=.076, \mathrm{p}$ $\left.=.006, R_{a d j}^{2}=.028, F=14.44\right)$.

The NIM index did not remain a significant predictor of LTL when individually controlling for years of daily smoking. The NIM index remained a significant predictor of LTL $\left(\beta=.067, \mathrm{p}=.013, R_{a d j}^{2}=.004, F=6.20\right)$ when not controlling for WBC.

After exclusion of 13 outlier cases $(\mathrm{N}=1359)$ suspected of IBI measurement error (as described in section 2.3.7), the NIM index was still a significant predictor of LTL $(\beta=.083, p$ $\left.=.002, R_{a d j}^{2}=.030, F=22.30\right)$ when controlling for $\mathrm{WBC}$.

\subsection{Relationship between the vmHRV, CRP and LTL, and between NIM index and LTL in reduced dataset}


bioRxiv preprint doi: https://doi org/10.1101/2022.02 17.480574; this version posted February 22,2022 . The copyright holder for this preprint (which was not certified by peer review) is the author/funder, who has granted bioRxiv a license to display the preprint in perpetuity. It is made available under aCC-BY-NC-ND 4.0 International license.

To account for directionality and confounder effects on results, analyses where repeated where all participants where confounders were present were excluded $(n=169)$. Descriptive statistics for the reduced dataset can be found in Table 6 .

Table 6 Descriptive statistics for vmHRV, NIM index, LTL, CRP, Leukocyte count, and Time since last meal in reduced dataset

\begin{tabular}{lccccc}
\hline Variable & Mean & Std. & Minimum & Maximum & n \\
\hline RMSSD & 37.81 & 58.88 & 4 & 563 & 169 \\
RMSSD_log10 & 1.38 & .35 & .60 & 2.75 & 169 \\
HFHRV & 654.51 & 3938.39 & 1 & 48970 & 169 \\
HFHRV_log10 & 1.83 & .73 & .17 & 4.69 & 169 \\
NIM & 354.88 & 1611.61 & .45 & 19203.73 & 169 \\
NIM_log10 & 1.63 & .82 & -.34 & 4.28 & 169 \\
LTL & 1.32 & .58 & 0 & 4 & 169 \\
LTL_log10 & .08 & .18 & -.45 & .65 & 169 \\
CRP & 2.62 & 4.36 & 0 & 38 & 169 \\
CRP_log10 & .20 & .38 & -.57 & 1.58 & 169 \\
WBC & 5.88 & 1.43 & .10 & 1.06 & 168 \\
WBC_log10 & .75 & 1.62 & 0 & 9 & 168 \\
Time since last meal & 3.27 & .30 & 169 \\
\hline Notes. RMSSD & Root mean & & & \\
\hline
\end{tabular}

Notes. RMSSD $=$ Root mean square of successive differences. $\_\log 10=\log 10$ transformed variable. HFHRV $=$ High frequency component heart rate variability. NIM $=$ Neuroimmunomodulation index. LTL $=$ Leukocyte telomere length arbitrary units. $\mathrm{CRP}=\mathrm{C}$-Reactive Protein. $\mathrm{WBC}=$ Leukocyte count.

When excluding all participants that reported sleeping problems, symptoms of depression, smoking or smokeless tobacco use, drinking more than 2-3 days per week, consuming more than four units of alcohol when drinking, and consuming six or more units of alcohol once or more per week, the NIM index $\left(\beta=.170, \mathrm{p}=.025, R^{2}{ }_{a d j}=.076, F=7.84\right)$ remained a significant predictor of LTL, but not HFHRV nor CRP, when controlling for WBC. The NIM index remained a significant predictor of LTL when simultaneously controlling for time since last meal and $\operatorname{WBC}\left(\beta=.170, \mathrm{p}=.026, R^{2}{ }_{a d j}=.070, F=5.19\right)$.

\section{NIM index regression model}
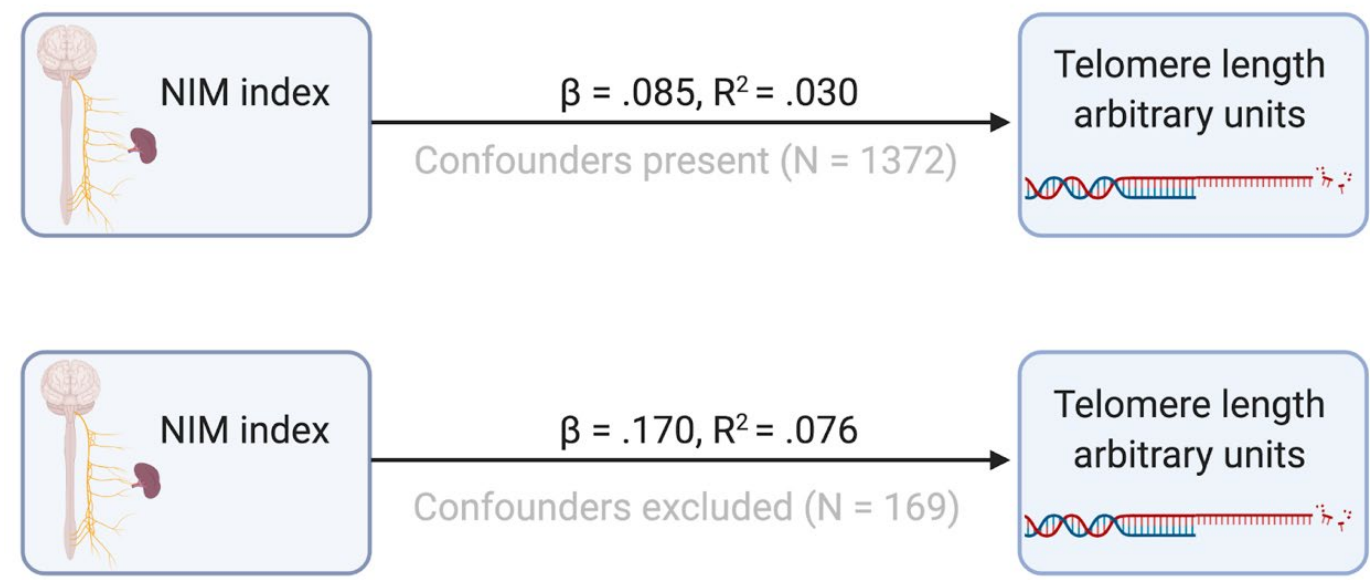

Figure 4 | Regression model for the relationship between NIM index and telomere length. All relationships controlling for leukocyte count. Figure created with BioRender.com. 
After exclusion of 4 outlier cases $(\mathrm{N}=165)$ suspected of IBI measurement error (as described in section 2.3.7), the NIM index was still a significant predictor of LTL $(\beta=.162, \mathrm{p}$ $\left.=.033, R_{a d j}^{2}=.081, F=8.17\right)$ when controlling for WBC. The NIM index remained a significant predictor of LTL when simultaneously controlling for time since last meal and $\mathrm{WBC}(\beta=.162$, $\left.\mathrm{p}=.035, R_{a d j}^{2}=.075, F=5.42\right)$.

\section{Discussion}

This is the first study to assess inflammation as a mediator in the relationship between vmHRV and telomere length, and to assess the relationship between the NIM index, a recently proposed index for vagal immunomodulation (Gidron et al., 2018) and possible indicator of PAS axis activity, and telomere length. It is also the first paper to conceptualize the neural substrate of these relationships anatomically as the PAS axis.

In the initial correlation analysis (Table 3), the effects of the positive association between vmHRV and telomere length were equal to the effect of the negative association between vmHRV and CRP. In our mediation analysis (Table 4), when controlling for WBC, we found that vmHRV had a direct positive effect on telomere length and a negative effect on CRP levels, while CRP had a negative effect on telomere length. These findings are in line with the hypothesis that inflammation is a negative mediator in the relationship between telomere length and vagal tone (Ask et al., 2018) and supports previous findings suggesting relationship between vmHRV and inflammation (Williams et al., 2019), vmHRV and telomere length (Perseguini et al., 2015; Streltsova et al., 2017; Woody et al., 2017; Zalli et al., 2013), and CRP and telomere length (Rode et al., 2014; Shin et al., 2019; Wong et al., 2014). The combined positive effects of vmHRV on CRP, and negative effects of CRP on telomere length via the indirect pathway almost cancel each other out, further suggesting that the balance between PAS axis activity and inflammatory output helps to preserve telomere integrity. Taken together, these mediation analyses provide partial statistical support for the hypothesis that inflammation mediates the relationship between vagal tone and telomere length as proposed by the NISIM (Ask et al., 2018).

Traditional mediation analyses have been critiqued for being too dependent on subjective interpretation (e.g. Agler \& De Boeck, 2017). This could be a challenge in the present study, as vagal tone by itself is not a measure of inflammation, nor is CRP a measure of vagal tone. Evidence indicates that CRP is an important regulator of inflammation (Sproston \& Ashworth, 2018), suggesting confounding effects that could partially de-couple its relationship with telomere length from PAS axis activity in the present study. The role of CRP in inflammation is not straightforward with sometimes opposing effects being ascribed to pentameric native CRP (nCRP) versus monomeric CRP (mCRP), the former isoform having primarily anti-inflammatory effects while mCRP having mainly pro-inflammatory effects (Sproston \& Ashwort, 2018). In our study, CRP isoform was not specified, thus, the mediation analysis might therefore not provide sufficient sensitivity to properly examine the relationships of interest. One thing to keep in mind when using HRV indicators of vagal tone is that, while the sympathetic nervous system acts as a unit, the parasympathetic nervous system does not. Thus, there is arguably going to be some level of dissociation between vagal input to the heart 
bioRxiv preprint doi: https://doi.org/10.1101/2022.02.17.480574; this version posted February 22, 2022. The copyright holder for this preprint (which was not certified by peer review) is the author/funder, who has granted bioRxiv a license to display the preprint in perpetuity. It is made available under aCC-BY-NC-ND 4.0 International license.

and vagal input to the spleen. The recently proposed NIM index (Gidron et al., 2018) is based on the ratio of vmHRV to CRP (vmHRV/CRP) and could serve as an indicator of prefrontally modulated vagal immunomodulation thus arguably be a better proxy for the PAS axis. In our regression analysis, we found that the NIM index was a stronger positive predictor of telomere length than vmHRV.

A huge problem with studies on the relationship between inflammation and vagal tone is that they do not control for time since the last meal, sleeping habits and problems, depression, and alcohol and tobacco use (Haensel et al., 2008; Papaioannou et al., 2013). One strength of this study was that we controlled for these confounders. In our mediation analysis, all relationships remained significant for 4 of 18 confounding variables; vmHRV remained a significant positive predictor of telomere length for 7 out of 17 confounding variables, while CRP remained a significant negative predictor of telomere length for 11 out of 17 confounding variables. The NIM index remained a significant positive predictor of telomere length when controlling for 16 of 17 confounding variables. These results can be interpreted in several ways.

Depression is associated with lower PFC activity, and reduced PFC function is a suggested risk factor for development of depression (Hare \& Duman, 2020; Kaya \& McCabe, 2019). Tobacco use is associated with altered nicotinic acetylcholine receptor availability in the PFC (Brody et al., 2016; Feduccia et al., 2012) which are integral to its function, especially in the dorsolateral PFC (DLPFC; Croxson et al., 2011; Yang et al., 2013). This area of the PFC is one of the PFC components with the clearest relationships with vmHRV (Brunoni et al., 2013; Nikolin et al., 2017). Both chronic and acute alcohol use is associated with reduced PFC functioning (Abernathy et al., 2010; Olsen et al., 2015). The development and maintenance of addictive behaviors including smoking is associated with reduced PFC functioning (Olsen et al., 2015). Sleeping problems are also associated with reduced PFC functioning (e.g Vartanian et al., 2014). One possible interpretation could thus be that the confounders represent individuals with reduced PFC integrity that by consequence are more prone to the behaviors and conditions indicated by control variables, and that these are indeed the individuals for which the effects would be the most pronounced. Going by this interpretation, the effect of the confounders may not have implications on the significance of the results. An alternative interpretation could be owed to the inflammatory responses that these conditions and behaviors would produce that are not a direct consequence of (reduced) PFC input to the vagus nerve. For instance, oral nicotine administration decreases vmHRV in healthy non-smokers (Sjoberg \& Saint, 2011), which, if independent of interactions with nicotinic receptors in the PFC could still have downstream effects on inflammatory marker expression. Inflammatory markers and ROS may have depressive effects on vmHRV, confounding the directionality of relationships (Lee MS et al., 2014). To account for these various interpretations, we did an additional regression analysis with a reduced dataset (from 1372 initial participants to 169) that excluded all participants where any of the confounders were present. In this dataset, only the NIM index remained a positive predictor of telomere length, and this relationship was significant after controlling for time since last meal. The explained variance and effect sizes in this reduced dataset were double of that which was observed in the initial dataset. The NIM index may therefore be a more sensitive proxy for the PAS axis and might mitigate some of the effects owed to lack of CRP isoform specification. After exclusion of some outlier cases suspected of 
bioRxiv preprint doi: https://doi.org/10.1101/2022.02.17.480574; this version posted February 22, 2022. The copyright holder for this preprint (which was not certified by peer review) is the author/funder, who has granted bioRxiv a license to display the preprint in perpetuity. It is made available under aCC-BY-NC-ND 4.0 International license.

measurement error, the NIM index remained a positive predictor of LTL in both the full and reduced dataset, indicating that this index is a robust indicator of PAS axis activity.

Due to the preliminary nature of the current findings and the indirect nature of variables that are used in the present study (and the possible implications this may have had for the reported effect sizes), it is premature to make any definite suggestions with regards to the clinical implications that the results may have. However, observations from the current literature on neurodegenerative diseases indicate PAS axis-associated relationships that are worthy of further exploration. The NISIM argues that PAS axis dysregulation will accelerate aging (Ask et al., 2018). The role of amyloid plaque in Alzheimer's disease is undecided with accumulating evidence indicating that it might not be the pathogenic trigger driving the neurodegenerative cascade (e.g. Sturchio et al., 2021). Alternative explanatory mechanisms that trigger and interact with known antecedents to neurodegenerative pathology are thus needed. Studies on senescent cells in the brain may offer plausible causative factors for neurodegeneration (Baker et al., 2011; Chinta et al., 2015). Recent studies indicated that increases in peripheral inflammation is a prodromal indicator of dementia, with greater cognitive impairment being associated with increased levels of IL-6 and TNF- $\alpha$ in Alzheimer's and Parkinson (King et al., 2017; Wood, 2018; see Maletic \& Raison (2014) for a review of how peripheral inflammatory signals can be transported into the brain in psychiatric disease). This may indicate that PAS axis-targeted interventions may protect against the development of age related disease in vulnerable populations.

While the effects proposed by the NISIM are small and accumulates over a lifetime in healthy populations (Ask et al., 2018), evidence from studies on cancer patients (Chiang et al., 2013; De Couck et al., 2013; Mouton et al., 2010, 2011, 2012), sepsis patients (de Castilho et al., 2018) and schizophrenic patients (Benjamin et al., 2020; North et al., 2021; Yu et al., 2008) indicate that the consequences of PAS axis dysfunction might be more severe in pathological conditions characterized by reduced prefrontally modulated vagal tone. If further validation of the NISIM is achieved, the findings in the above-mentioned clinical conditions may suggest avenues for neuroimmunomodulation treatments targeting the different levels of the PAS axis: (1) the level of the PFC, (2) the level of the ANS, (3) the level of the spleen and leukocytes, and at (4) the cognitive/behavioral level.

Future studies should determine the genes relevant for the development of the PFC's ability to modulate vagal tone such that regenerative genetic interventions for increasing the PFC's capacity for vagal modulation can be developed.

\subsection{Limitations and future perspectives}

The findings detailed in the present study have small effect sizes. Although the effects proposed by the NISIM are small and accumulate over the course of a lifetime (Ask et al., 2018), it is possible that some of the results can be attributed to the specific limitations of the current study. CRP may have opposing effects on inflammation depending on subtype (Sproston \& Ashwort, 2018) and transcriptional induction of CRP is downstream of IL-6 (Boras et al., 2014). It is thus hard to say how the results would have been if CRP type had been specified or if IL-6 had been assessed instead. The present study should be repeated with CRP subtype specified as well as for other inflammatory markers, particularly IL-6 as this marker may provide a better proxy for 
the inflammatory effects of a dysregulated PAS axis (Williams et al., 2019). Another limitation is that the recordings used to quantify vmHRV were 30 seconds long which is short. The recording should last for at least 10 times the wavelength of the lower frequency bound of the investigated component, and 5 minute recordings is the preferred standard. It has, however, been shown that useful frequency-domain information can be derived from recordings as low as $40 \mathrm{~s}$ for HFHRV (Salahuddin et al., 2007). The RMSSD and HFHRV indices were highly correlated in our study, which indicate that the measures were of good quality. Future studies should use 5 minute recordings to quantify vmHRV to reduce effects owing to suboptimal IBI measurements. A third limitation owes to the correlational nature of the study as it does not provide direct evidence for the NISIM. Evidence suggests that telomere dysfunction and senescence can occur irrespective of telomere length (Victorelli \& Passos et al., 2017). A recent study demonstrated that ROS-induced telomere dysfunction results in senescence by replication fork arrest (Coluzzi et al., 2019). Longitudinal studies are needed to assess the directional relationship between prefrontally modulated vagal tone, inflammatory markers, and telomere length, and should include markers of hydrogen peroxide induced telomere damage such as 8oxoguanine, indicators of replication fork stall such as $\gamma \mathrm{H} 2 \mathrm{AX}$ with respect to 53BP1 at telomeres, and increases in the H3K9me3 histone mark (Coluzzi et al., 2019). Assessing the relationship between indicators of PFC functioning and markers of oxidative DNA damage is important to disentangle directionality problems such as telomere dysfunction preceding reduced prefrontal function or vice versa (e.g. Powell et al., 2018). A final limitation of the present study is that we were not interested in the effects of sex and did therefore not include this variable in the dataset and analysis. There have been reports of sex differences in vmHRV (e.g. Koenig \& Thayer, 2016) and Alzheimer's impact and progression (Laws et al., 2018), thus, future studies should examine sex differences in PAS axis dysregulation and its clinical relevance.

\subsection{Conclusion}

This study is an important first step towards understanding the anatomical-to-molecular mechanisms that relate individual differences in neurocognitive stress regulation capacity to PAS axis-related induction of cellular senescence and age-related pathology. Our results indicate that inflammation is downstream of PAS axis activity, suggesting that PAS axis dysregulation leads to increased levels of inflammation and subsequently ROS induced telomere damage. Based on the findings of our study, we argue that the NIM index is a sensitive proxy for PAS axis activity and could serve as a useful indicator when assessing PAS axisrelated effects on antecedents to cellular senescence. Future studies should assess the relationship between indicators of prefrontally modulated vagal tone, IL-6, CRP subtype, and telomere length as well as more direct markers of oxidative telomere damage and telomere damage-induced cellular senescence.

\section{Acknowledgements}

We would like to thank our colleagues Leiv Arne Rosseland, Naomi Azulay, and Christian Tronstad for sharing their expertise and valuable comments that greatly improved the 
bioRxiv preprint doi: https://doi.org/10.1101/2022.02.17.480574; this version posted February 22, 2022. The copyright holder for this preprint (which was not certified by peer review) is the author/funder, who has granted bioRxiv a license to display the preprint in perpetuity. It is made available under aCC-BY-NC-ND 4.0 International license.

manuscript. We would particularly like to thank Leiv Arne Rosseland for help with organizing the study, Christian Tronstad for analysis of IBIs and quantification of HRV indices, and Naomi Azulay for help with detecting outliers in the HRV data. 
bioRxiv preprint doi: https://doi.org/10.1101/2022.02.17.480574; this version posted February 22, 2022. The copyright holder for this preprint (which was not certified by peer review) is the author/funder, who has granted bioRxiv a license to display the preprint in perpetuity. It is made available under aCC-BY-NC-ND 4.0 International license.

\section{References}

Abernathy, K., Chandler, L. J., \& Woodward, J. J. (2010). Alcohol and the prefrontal cortex. International Review of Neurobiology, 91, 289-320. https://doi.org/10.1016/S00747742(10)91009-X

Agler, R., \& De Boeck, P. (2017). On the interpretation and use of mediation: multiple perspectives on mediation analysis. Frontiers in Psychology, 8. doi:10.3389/fpsyg.2017.01984

Al Hazzouri, A. Z., Elfassy, T., Carnethon, M., Lloyd-Jones, D., and Yaffe, K. (2017). Heart rate variability and cognitive function in middle-aged adults: the cardia study. $J$. Alzheimer's Assoc., 13, 513-514. doi: 10.1016/j.jalz.2017.06.587

Alonso, A., Huang, X., Mosley, T. H., Heiss, G., and Chen, H. (2015). Heart rate variability and the risk of parkinson disease: the atherosclerosis risk in communities. Ann. Neurol., 77, 877-883. doi: 10.1002/ana.24393

Ask, T. F., Lugo, R. G., \& Sütterlin, S. (2018). The neuro-immuno-senescence integrative model (NISIM) on the negative association between parasympathetic activity and cellular senescence. Frontiers in Neuroscience, 12. https://doi.org/10.3389/fnins.2018.00726

Baker, D. J., Wijshake, T., Tchkonia, T., LeBrasseur, N. K., Childs, B. G., van de Sluis, B., et al. (2011). Clearance of p16Ink4a-positive senescent cells delays ageing-associated disorders. Nature, 479, 232-236. doi: 10.1038/nature10600

Baumeister, D., Akhtar, R., Ciufolini, S., Pariante, C. M., \& Mondelli, V. (2016). Childhood trauma and adulthood inflammation: a meta-analysis of peripheral C-reactive protein, interleukin-6 and tumour necrosis factor- $\alpha$. Mol Psychiatry, 21, 642-9. doi:10.1038/mp.2015.67

Benjamin, B. R., Valstad, M., Elvsåshagen, T., Jönsson, E. G., Moberget, T., Winterton, A., ... Quintana, D. S. (2020). Heart rate variability is associated with disease severity in psychosis spectrum disorders. Progress in Neuro-Psychopharmacology and Biological Psychiatry, 110108. doi:10.1016/j.pnpbp.2020.110108

Berntson, G. G., Lozano, D. L., and Chen, Y. J. (2005). Filter properties of root mean square successive difference (RMSSD) for heart rate. Psychophysiology, 42, 246-252. doi: 10.1111/j.1469-8986.2005.00277.x

Bissel, M. J., Kenny, P. A., \& Radisky, D. C. (2005). Microenvironmental regulators of tissue structure and function also regulate tumor induction and progression: the role of extracellular matrix and its degrading enzymes. Cold. Spring Harb. Symp. Quant. Biol., 70, 343-356. doi: 10.1101/sqb.2005.70.013

Blackburn, E. H. (1991). Telomeres. Trends Biochem Sci, 16, 378-381.

Boras E, Slevin M, Alexander MY, Aljohi A, Gilmore W, Ashworth J, et al. (2014). Monomeric C-reactive protein and Notch-3 co-operatively increase angiogenesis through PI3K signalling pathway. Cytokine, 69, 165-79. doi:10.1016/j.cyto.2014.05.027

Brody, A. L., Hubert, R., Mamoun, M. S., Enoki, R., Garcia, L. Y., Abraham, P., Young, P., \& Mandelkern, M. A. (2016). Nicotinic acetylcholine receptor availability in cigarette smokers: effect of heavy caffeine or marijuana use. Psychopharmacology, 233(17), 3249-3257. https://doi.org/10.1007/s00213-016-4367-x 
bioRxiv preprint doi: https://doi.org/10.1101/2022.02.17.480574; this version posted February 22, 2022. The copyright holder for this preprint (which was not certified by peer review) is the author/funder, who has granted bioRxiv a license to display the preprint in perpetuity. It is made available under aCC-BY-NC-ND 4.0 International license.

Brosschot, J. F., Pieper, S., \& Thayer, J. F. (2005). Expanding stress theory: prolonged activation and perseverative cognition. Psychoneuroendocrinology, 30, 1043-1049. doi: 10.1016/j.psyneuen.2005.04.008

Brunoni, A.R., et al., (2013). Polarity-and valence-dependent effects of prefrontal transcranial direct current stimulation on heart rate variability and salivary cortisol.

Psychoneuroendocrinology, 38(1), 58-66.

Campisi, J. (2000). Cancer, aging and cellular senescence. In Vivo, 14(1), 183-188.

Campisi, J. (2003). Cancer and ageing: rival demons? Nature Reviews Cancer, 3(5), 339-349. doi: $10.1038 / \mathrm{nrc} 1073$

Campisi, J. (2013). Aging, cellular senescence, and cancer. Annu Rev Physiol, 75, 685-705. Doi:10.1146/annurev-physiol-030212-183653.

Chiang, J. K., Kuo, T. B., Fu, C. H., \& Koo, M. (2013). Predicting 7-day survival using heart rate variability in hospice patients with non-lung cancers. PLoS One, 8(7), e69482.

Chinta, S. J., Woods, G., Rane, A., Demaria, M., Campisi, J., \& Andersen, J. K. (2015). Cellular senescence and the aging brain. Exp. Gerontol., 68, 3-7.

Doi:10.1016/j.exger.2014.09.018

Cropley, M., \& Collis, H. (2020). The association between work-related rumination and executive function using the behavior rating inventory of executive function. Frontiers in Psychology, 11, 821. https://doi.org/10.3389/fpsyg.2020.00821

Cropley, M., Plans, D., Morelli, D., Sütterlin, S., Inceoglu, I., Thomas, G., \& Chu, C. (2017). The association between work-related rumination and heart rate variability: A field study. Frontiers in Human Neuroscience, 11, 27.

https://doi.org/10.3389/fnhum.2017.00027

Croxson, P. L., Kyriazis, D. A., \& Baxter, M. G. (2011). Cholinergic modulation of a specific memory function of prefrontal cortex. Nat Neurosci., 14(12), 1510-1512.

de Castilho, F. M., Ribeiro, A., Nobre, V., Barros, G., \& de Sousa, M. R. (2018). Heart rate variability as predictor of mortality in sepsis: A systematic review. PloS one, 13(9), e0203487. https://doi.org/10.1371/journal.pone.0203487

De Couck, M., Maréchal, R., Moorthamers, S., Van Laethem, J.-L., \& Gidron, Y. (2015).

Vagal nerve activity predicts overall survival in metastatic pancreatic cancer, mediated by inflammation. Cancer Epidemiology, 40, 47-51.

De Couck, M., van Brummelen, D., Schallier, D., De Grève, J., \& Gidron, Y. (2013). The relationship between vagal nerve activity and clinical outcomes in prostate and nonsmall cell lung cancer patients. Oncology Reports, 30(5), 2435-2441.

Deegan, B. M., O’Connor, M., Lyons, D., O'Laighin, G. (2007a). A new blood pressure and heart rate signal analysis technique to assess Orthostatic Hypotension and its subtypes. Conf Proc IEEE Eng Med Biol Soc, 2007, 935-938.

Deegan, B. M., O’Connor, M., Lyons, D., O'Laighin, G. (2007b). Development and e valuation of new blood pressure and heart rate signal analysis techniques to assess orthostatic hypotension and its subtypes. Physiol Meas, 28, N87-N102.

Epel, E. S., Blackburn, E. H., Lin, J., Dhabhar, F. S., Adler, N. E., Morrow, J. D., Cawthon, R. M. (2004). Accelerated telomere shortening in response to life stress. PNAS, 101(49), 17312-17215. Doi:10.1073/pnas.0407162101

Epel, E. S., Daubenmier, J., Moskowitz, J. T., Folkman, S., \& Blackburn, E. (2009). 
bioRxiv preprint doi: https://doi.org/10.1101/2022.02.17.480574; this version posted February 22, 2022. The copyright holder for this

Can meditation slow rate of cellular aging? Cognitive stress, mindfulness, and telomeres. Ann. N. Y. Acad. Sci., 1172, 34-53. Doi:10.1111/j.1749-6632.2009.04414.x

Eggen, A. E., Mathiesen, E. B., Wilsgaard, T., Jacobsen, B. K., \& Njølstad, I. (2013). The sixth survey of the Tromsø Study (Tromsø 6) in 2007-08: Collaborative research in the interface between clinical medicine and epidemiology: Study objectives, design, data collection procedures, and attendance in a multipurpose population-based health survey. Scandinavian Journal of Public Health, 41(1), 65-80. doi:10.1177/1403494812469851

Feduccia, A. A., Chatterjee, S., \& Bartlett, S. E. (2012). Neuronal nicotinic acetylcholine receptors: neuroplastic changes underlying alcohol and nicotine addictions. Frontiers in Molecular Neuroscience, 5, 83. https://doi.org/10.3389/fnmol.2012.00083

Felten, S. Y., and Felten, D. L. (1994). Neural-immune interactions. Prog. Brain Res., 100, 157-162. doi: 10.1016/S0079-6123(08)60781-5

Fitzpatrick, A. L., Kronmal, R. A., Gardner, J. P., Psaty, B. M., Jenny, N. S., et al. (2007). Leukocyte telomere length and cardiovascular disease in the cardiovascular health study. Am J Epidemiol, 165, 14-21.

Gidron, Y., De Couck, M., Schallier, D., De Greve, J., Van Laethem, J. L., \& Maréchal, R. (2018). The Relationship between a new biomarker of vagal neuroimmunomodulation and survival in two fatal cancers. Journal of Immunology Research, 2018, 1-5. doi:10.1155/2018/4874193

Gidron, Y., Perry, H., \& Glennie, M. (2005). Does the vagus nerve inform the brain about preclinical tumours and modulate them?. The Lancet Oncology, 6(4), 245-248.

Goedhart, A. D., van der Sluis, S., Houtveen, J. H., Willemsen, G., \& de Geus, E. J. (2007). Comparison of time and frequency domain measures of RSA in ambulatory recordings. Psychophysiology 44, 203-215. doi: 10.1111/j.1469-8986.2006.00490.x

Golkar, A., Lonsdorf, T. B., Olsson, A., Lindstrom, K. M., Berrebi, J., Fransson, P., et al. (2012). Distinct contributions of the dorsolateral prefrontal and orbitofrontal cortex during emotion regulation. PLoS One, 7, e48107. doi: 10.1371/journal.pone.0048107

Gross, J. J. (1998). The emerging field of emotion regulation: An integrative review. Review of General Psychology, 2(3), 271-299. doi:10.1037/1089-2680.2.3.271

Haensel, A., Mills, P. J., Nelesen, R. A., Ziegler, M. G., and Dimsdale, J. E. (2008). The relationship between heart rate variability and inflammatory markers in cardiovascular diseases. Psychoneuroendocrinology, 33, 1305-1312. doi: 10.1016/j.psyneuen.2008.08.007

Hare, B. D., \& Duman, R. S. (2020). Prefrontal cortex circuits in depression and anxiety: contribution of discrete neuronal populations and target regions. Molecular Psychiatry. doi:10.1038/s41380-020-0685-9

Hildebrandt, L. K., McCall, C., Engen, H. G., and Singer, T. (2016). Cognitive flexibility, heart rate variability, and resilience predict fine-grained regulation of arousal during prolonged threat. Psychophysiology 53, 880-890. doi: 10.1111/psyp.12632

Huston, J. M., Ochani, M., Rosas-Ballina, M., Liao, H., Ochani, K., Pavlov, V. A., et al. (2006). Splenectomy inactivates the cholinergic anti-inflammatory pathway during lethal endotoxemia and polymicrobial sepsis. J. Exper. Med., 203, 1623-1628. doi: $10.1084 /$ jem.20052362 
bioRxiv preprint doi: https://doi org/10.1101/2022.02.17.480574; this version posted February 22, 2022. The copyright holder for this

Irwin, M. R., Olmstead, R., \& Carroll, J. E. (2016). Sleep disturbance, sleep duration, and inflammation: A systematic review and meta-analysis of cohort studies and experimental sleep deprivation. Biological Psychiatry, 80(1), 40-52. https://doi.org/10.1016/j.biopsych.2015.05.014

Jennings, J. R., Sheu, L. K., Kuan, D. C. H., Manuck, S. B., and Gianaros, P. J. (2016). Resting state connectivity of the medial prefrontal cortex covaries with individual differences in high-frequency heart rate variability. Psychophysiology, 53, 444-454. Doi: $10.1111 /$ psyp. 12586

Kane, A. E., \& Sinclair, D. A. (2019). Epigenetic changes during aging and their reprogramming potential. Critical Reviews in Biochemistry and Molecular Biology, 54(1), 61-83. https://doi.org/10.1080/10409238.2019.1570075

Kaya, S., \& McCabe, C. (2019). What role does the prefrontal cortex play in the processing of negative and positive stimuli in adolescent depression?. Brain Sciences, 9(5), 104. https://doi.org/10.3390/brainsci9050104

Kennedy, B., Fang, F., Valdimarsdóttir, U., Udumayan, R., Montgomery, S., \& Fall, K. (2017). Stress resilience and cancer risk: a nationwide cohort study. J. Epidemiol. Commun. Health, 71, 947-953. doi: 10.1136/jech-2016-208706

Kim, D. H., Lipsitz, L. A., Ferrucci, L., Varadhan, R., Guralnik, J. M., Carlson, M. C., et al. (2006). Association between reduced heart rate variability and cognitive impairment in older disabled women in the community: women's health and aging study i. J. Am. Geriatr. Soc. 54, 1751-1757. doi: 10.1111/j.1532-5415.2006.00940.x

King, E., O’Brien, J. T., Donaghy, P., Morris, C., Barnett, N., Olsen, K., ... Thomas, A. J. (2017). Peripheral inflammation in prodromal Alzheimer's and Lewy body dementias. Journal of Neurology, Neurosurgery \& Psychiatry, 89(4), 339-345. doi:10.1136/jnnp2017-317134

Koenig, J., \& Thayer, J. F. (2016). Sex differences in healthy human heart rate variability: A meta-analysis. Neuroscience \& Biobehavioral Reviews, 64, 288-

310. doi:10.1016/j.neubiorev.2016.03.007

Kraynak, T. E., Marsland, A. L., Wager, T. D., \& Gianaros, P. J. (2018). Functional neuroanatomy of peripheral inflammatory physiology: A meta-analysis of human neuroimaging studies. Neuroscience \& Biobehavioral Reviews, 94, 76-92. doi:10.1016/j.neubiorev.2018.07.013

Kroenke, C. H., Epel, E., Adler, N., Bush, N. R., Obradovic, J., Lin, J., et al. (2011). Autonomic and adrenocortical reactivity and buccal cell telomere length in kindergarten children. Psychosom. Med., 73, 533-540. doi: 10.1097/PSY.0b013e318229acfc

Laws, K. R., Irvine, K., Gale, T. M. (2018). Sex differences in Alzheimer's disease. Curr Opin Psychiatry., 31(2), 133-139. doi: 10.1097/YCO.0000000000000401

Lee, C. H., \& Giuliani, F. (2019). The role of inflammation in depression and fatigue. Frontiers in immunology, 10, 1696. https://doi.org/10.3389/fimmu.2019.01696

Lee, M. S., Eum, K. D., Fangm, S. C., Rodrigues, E. G., Modest, G. A., and Christiani, D. C. (2014). Oxidative stress and systemic inflammation as modifiers of cardiac autonomic responses to particulate air pollution. Int. J. Cardiol., 176, 166-170. doi: 10.1016/j.ijcard.2014.07.012 
bioRxiv preprint doi: https://doi.org/10.1101/2022.02.17.480574; this version posted February 22, 2022. The copyright holder for this

Liu, Y. Z., Wang, Y. X., \& Jiang, C. L. (2017). Inflammation: the common pathway of stressrelated diseases. Frontiers in human neuroscience, 11, 316. https://doi.org/10.3389/fnhum.2017.00316

López-Otín, C., Blasco, M.A., Partridge, L., Serrano, M., \& Kroemer, G. (2013). The hallmarks of aging. Cell, 153(6), 1194-1217. Doi:10.1016/j.cell.2013.05.039.

Madden, K. S., Sanders, V. M., and Felten, D. L. (1995). Catecholamine influences and sympathetic neural modulation of immune responsiveness. Annu. Rev. Pharmacol. Toxicol., 35, 417-448. doi: 10.1146/annurev.pa.35.040195.002221

Maletic, V., and Raison, C. (2014). Integrated neurobiology of bipolar disorder. Front. Psychiatry, 5, 98. doi: 10.3389/fpsyt.2014.00098

Marinac, C. R., Sears, D. D., Natarajan, L., Gallo, L. C., Breen, C. I., \& Patterson, R. E. (2015). Frequency and circadian timing of eating may influence biomarkers of inflammation and insulin resistance associated with breast cancer risk., PloS one, 10(8), e0136240. https://doi.org/10.1371/journal.pone.0136240

Martínez, C. A. G., Quintana, A. O., Vila, X. A., Touriño, M. J. L., Rodríguez-Liñares, L., Presedo, J. M. R., \& Penín, A. J. M. (2017). Heart rate variability Analysis with the R package RHRV. Use R!. Berlin: Springer.

Masi, S., Nightingale, C. M., Day, I. N., Guthrie, P., Rumley, A., et al. (2012). Inflammation and not cardiovascular risk factors is associated with short leukocyte telomere length in 13- to 16-year-old adolescents. Arterioscler Thromb Vasc Biol, 32, 2029-2034.

MATLAB. (2015). Version 8.5 (R2015a). Natick, Massachusetts: The MathWorks Inc.

Maydych, V. (2019). The interplay between stress, inflammation, and emotional attention: relevance for depression. Frontiers in Neuroscience, 13, 384.

https://doi.org/10.3389/fnins.2019.00384

Morey, J. N., Boggero, I. A., Scott, A. B., \& Segerstrom, S. C. (2015). Current directions in stress and human immune function. Current Opinion in Psychology, 5, 13-17. https://doi.org/10.1016/j.copsyc.2015.03.007

Moriarity, D. P., Ng, T., Titone, M. K., Chat, I. K., Nusslock, R., Miller, G. E., \& Alloy, L. B. (2019). Reward responsiveness and ruminative styles interact to predict inflammation and mood symptomatology. Behavior Therapy, 51(5), 829-842. doi:10.1016/j.beth.2019.11.007

Mouton, C., Ronson, A., Razavi, D., Delhaye, F., Kupper, N., Paesmans, M., ... Gidron, Y. (2012). The relationship between heart rate variability and time-course of carcinoembryonic antigen in colorectal cancer. Autonomic Neuroscience, 166(1-2), 96-99. doi:10.1016/j.autneu.2011.10.002

Mouton, C., Ronson, A., Razavi, D., Nougaret, J-M., Delhaye, F., Hendliez, A., \& Gidron, Y. (2010). The relationship between heart rate variability and prognosis in two cancers. Int J Mol Med, 26, 9-9.

Mouton, C., Ronson, A., Razavi, D. et al., (2012). The relationship between heart rate variability and time-course of carcinoembryonic antigen in colorectal cancer. Autonomic Neuroscience: Basic \& Clinical, 166(1-2), 96-99.

Neuner, B., Lenfers, A., Kelsch, R., Jäger, K., Brüggmann, N., van der Harst, P., \& Walter, M. (2015). Telomere length is not related to established cardiovascular risk factors but 
bioRxiv preprint doi: https://doi.org/10.1101/2022.02.17.480574; this version posted February 22, 2022. The copyright holder for this

does correlate with red and white blood cell counts in a german blood donor population. PLOS ONE, 10(10), e0139308. doi:10.1371/journal.pone.0139308

Nikolin, S., Boonstra, T. W., Loo, C. K., \& Martin, D. (2017). Combined effect of prefrontal transcranial direct current stimulation and a working memory task on heart rate variability. PLoS One, 12, e0181833. doi: 10.1371/journal.pone.0181833

Noble, B. T., Brennan, F. H., \& Popovich, P. G. (2018). The spleen as a neuroimmune interface after spinal cord injury. Journal of Neuroimmunology, 321, 1-11. doi:10.1016/j.jneuroim.2018.05.007

North, H.F., Bruggemann, J., Cropley, V., Swaminathan, V., Sundram, S., Lenroot, R., Pereira, A. M., Zalesky, A., Bousman, C., Pantelis, C., Weickert, T. W., \& Shannon Weickert, C. (2021). Increased peripheral inflammation in schizophrenia is associated with worse cognitive performance and related cortical thickness reductions. Eur Arch Psychiatry Clin Neurosci., 271(4), 595-607. doi: 10.1007/s00406-021-01237-z.

O'Callaghan, N. J., \& Fenech, M. (2011). A quantitative PCR method for measuring absolute telomere length. Biological Procedures Online, 13, 3. https://doi.org/10.1186/14809222-13-3

O'Donovan, A., Pantell, M. S., Puterman, E., Dhabhar, F. S., Blackburn, E. H., et al. (2011) Cumulative inflammatory load is associated with short leukocyte telomere length in the Health, Aging and Body Composition Study. PLoS One, 6, e19687

Olsen, V., Lugo, R., \& Sütterlin, S. (2015). The somatic marker theory in the context of addiction: contributions to understanding development and maintenance. Psychology Research and Behavior Management, 187. doi:10.2147/prbm.s68695

Papaioannou, V., Pneumatikos, I., and Maglaveras, N. (2013). Association of heart rate variability and inflammatory responses in patients with cardiovascular diseases: current strenghts and limitations. Front. Physiol., 4(174). doi:10.3389/fphys.2013.00174

Perseguini, N. M., Verlengia, R., Milan, J. C., Minatel, V., Rehder-Santos, P., Takahashi, A. C. M., et al. (2015). Cardiac autonomic modulation, C-reactive protein or telomere length: which of these variables has greater importance to aging? Int. J. Cardiol., 178, 79-81. doi:10.1016/j.ijcard.2014.10.123

Piccirillo, G., Bucca, C., Bauco, C., Cinti, A. M., Michele, D., Fimognari, L. F., et al. (1998). Power spectral analysis of heart rate in subjects over a hundred years old. Int. J. Cardiol., 63, 53-61. doi:10.1016/S0167-5273(97)00282-9

Pinquart, M., \& Duberstein, P. R. (2010). Depression and cancer mortality: a meta-analysis. Psychological Medicine, 40(11), 1797-1810. https://doi.org/10.1017/S0033291709992285

Powell, T. R., De Jong, S., Breen, G., Lewis, C. M., \& Dima, D. (2018). Telomere length as a predictor of emotional processing in the brain. Human Brain Mapping. doi:10.1002/hbm.24487

Pradhan, A. D., Manson, J.E., Rifai, N., Buring, J. E., \& Ridker, P. M. (2001). C-reactive protein, interleukin 6, and risk of developing type 2 diabetes mellitus. $J$ Am Med Assoc., 286(3), 327-34. doi:10.1001/jama.286.3.327

R Core Team. (2020). R: A language and environment for statistical computing. R Foundation for Statistical Computing: Vienna, Austria. https:/www.R-project.org/. 
bioRxiv preprint doi: https://doi.org/10.1101/2022.02.17.480574; this version posted February 22, 2022. The copyright holder for this

Rao, S. G., \& Jackson, J. G. (2016). SASP: tumor suppressor or promoter? Yes! Trends Cancer, 2, 676-687. doi: 10.1016/j.trecan.2016.10.001

Rico-Uribe, L. A., Caballero, F. F., Martín-María, N., Cabello, M., Ayuso-Mateos, J. L., \& Miret, M. (2018). Association of loneliness with all-cause mortality: A meta-analysis. PloS one, 13(1), e0190033. https://doi.org/10.1371/journal.pone.0190033

Rode, L., Nordestgaard, B. G., Weischer, M., \& Bojesen, S. E. (2014). Increased body mass index, elevated c-reactive protein, and short telomere length. The Journal of Clinical Endocrinology \& Metabolism, 99(9), E1671-E1675. doi:10.1210/jc.2014-1161

Rosas-Ballina, M., Ochani, M., Parrish, W. R., Ochani, K., Harris, Y. T., Huston, J. M., et al. (2008). Splenic nerve is required for cholinergic antiinflammatory pathway control of TNF in endotoxemia. Proc. Natl. Acad. Sci. U.S.A., 105, 11008-11013. doi: $10.1073 /$ pnas.0803237105

Rufer, N., Dragowska, W., Thornbury, G., Roosnek, E., \& Lansdorp, P. M. (1998). Telomere length dynamics in human lymphocyte subpopulations measured by flow cytometry. Nat Biotechnol, 16, 743-747.

Salahuddin, L., Cho, J., Jeong, M. G., \& Kim, D. (2007). Ultra short term analysis of heart rate variability for monitoring mental stress in mobile settings. 2007 29th Annual International Conference of the IEEE Engineering in Medicine and Biology Society. doi:10.1109/iembs.2007.4353378

Santos, C. Y., Snyder, P. J., Wu, W.-C., Zhang, M., Echeverria, A., \& Alber, J. (2017). Pathophysiologic relationship between Alzheimer's disease, cerebrovascular disease, and cardiovascular risk: a review and synthesis. Alzheimer's \& Dementia: Diagn. Assessm. Dis. Monitor., 7, 69-87. doi: 10.1016/j.dadm.2017.01.005

Schistad, E. I., Stubhaug, A., Furberg, A.-S., Engdahl, B. L., \& Nielsen, C. S. (2017). Creactive protein and cold-pressor tolerance in the general population. $P A I N, 158(7)$, 1280-1288. doi:10.1097/j.pain.0000000000000912

Schreck, R., \& Bauerle, P. A. (1994). Assessing oxygen radicals as mediators in activation of inducible eukaryotic transcription factor NF-kB. Methods Enzymol., 234, 151-163. doi:10.1016/0076-6879(94)34085-4

Seeley, W. W., Menon, V., Schatzberg, A. F., Keller, J., Glover, G. H., Kenna, H., et al. (2007). Dissociable intrinsic connectivity networks for salience processing and executive control. J. Neurosci., 27, 2349-2356.

doi: 10.1523/JNEUROSCI.5587-06.2007

Semple, S., Cowlishaw, G., \& Bennett, P. M. (2002). Immune system evolution among anthropoid primates: parasites, injuries and predators. Proceedings of the Royal Society B: Biological Sciences, 269(1495), 1031-1037. doi:10.1098/rspb.2001.1950

Shimizu, K., Arai, Y., Hirose, N., Yonemoto, T., and Wakida, Y. (2002). Prognostic significance of heart rate variability in centenarians. Clin. Exp. Hypertens., 24, 91-98. doi: 10.1081/CEH-100108719

Shin, D., Shin, J., \& Lee, K. W. (2019). Effects of inflammation and depression on telomere length in young adults in the United States. Journal of Clinical Medicine, 8(5), 711. https://doi.org/10.3390/jcm8050711 
bioRxiv preprint doi: https://doi.org/10.1101/2022.02.17.480574; this version posted February 22, 2022. The copyright holder for this preprint (which was not certified by peer review) is the author/funder, who has granted bioRxiv a license to display the preprint in perpetuity. It is made available under aCC-BY-NC-ND 4.0 International license.

Sjoberg, N., \& Saint, D. A. (2011). A single $4 \mathrm{mg}$ dose of nicotine decreases heart rate variability in healthy nonsmokers: Implications for smoking cessation programs. Nicotine \& Tobacco Research, 13(5), 369-372. doi:10.1093/ntr/ntr004

Streltsova, L. I., Tkacheva,Î.V., Plokhova, E. V., Akasheva, D. U., Strazhesko, I. D., Dudinskaya, E., et al. (2017). Age-related changes in heart rate variability and their relation with leucocyte telomere length. Cardiovasc. Ther. Prevent., 16, 54-60. doi: 10.15829/1728-8800-2017-1-54-60

Sturchio, A., Dwivedi, A. K., Young, C. B., Malm, T., Marsili, L., Sharma, J. S., Mahajan, A., Hill, E. J., El Andaloussi, S., Poston, K. L., Manfredsson, F. P., Schneider, L. S, Ezzat, K., \& Espay, A. J. (2021). High cerebrospinal amyloid-b 42 is associated with normal cognition in individuals with brain amyloidosis. EClinicalMedicine, 000(2021), 100988. https://doi.org/10.1016/j.eclinm.2021.100988

Task Force of the European Society of Cardiology and the North American Society of Pacing and Electrophysiology (1996). Heart rate variability: standards of measurement, physiological interpretation and clinical use. Circulation, 93, 1043-1065. doi: 10.1161/01.CIR.93.5.1043

Tchkonia, T., Zhu, Y., van Deursen, J., Campisi, J., and Kirkland, J. L. (2013). Cellular senescence and the senescent secretory phenotype: therapeutic opportunities. J. Clin. Investig., 123, 966-972. doi: 10.1172/JCI64098

Thayer, J. F., Åhs, F., Fredrikson, M., Sollers, J. J., and Wager, T. D. (2012). A meta-analysis of heart rate variability and neuroimaging studies: implications for heart rate variability as a marker of stress and health. Neurosci. Biobehav. Rev., 36, 747-756. Doi:10.1016/j.neubiorev.2011.11.009

Thayer, J. F., \& Lane, R. D. (2000). A model of neurovisceral integration in emotion regulation and dysregulation. J. Affect. Disord., 61, 201-216. doi: 10.1016/S01650327(00)00338-4

Thomas, P., O' Callaghan, N. J., \& Fenech, M. (2008). Telomere length in white blood cells, buccal cells and brain tissue and its variation with ageing and Alzheimer's disease. Mechanisms of Ageing and Development, 129(4), 183-190. doi:10.1016/j.mad.2007.12.004

Tibuakuu, M., Kamimura, D., Kianoush, S., DeFilippis, A. P., Al Rifai, M., Reynolds, L. M., White, W. B., Butler, K. R., Mosley, T. H., Turner, S. T., Kullo, I. J., Hall, M. E., \& Blaha, M. J. (2017). The association between cigarette smoking and inflammation: The Genetic Epidemiology Network of Arteriopathy (GENOA) study. PloS one, 12(9), e0184914. https://doi.org/10.1371/journal.pone.0184914

Tracey, K. J. (2002). The inflammatory reflex. Nature, 420(6917), 853-859.

Tracey, K. J. (2007). Physiology and immunology of the cholinergic anti-inflammatory pathway. J. Clin. Investig. 117, 289-296. doi: 10.1172/JCI30555

van de Loo, A., Mackus, M., Kwon, O., Krishnakumar, I. M., Garssen, J., Kraneveld, A. D., Scholey, A., \& Verster, J. C. (2020). The inflammatory response to alcohol consumption and its role in the pathology of alcohol hangover. Journal of Clinical Medicine, 9(7), 2081. https://doi.org/10.3390/jcm9072081

Vartanian, O., Bouak, F., Caldwell, J. L., Cheung, B., Cupchik, G., Jobidon, M. E., Lam, Q., Nakashima, A., Paul, M., Peng, H., Silvia, P. J., \& Smith, I. (2014). The effects of a 
bioRxiv preprint doi: https://doi.org/10.1101/2022.02.17.480574; this version posted February 22, 2022. The copyright holder for this

single night of sleep deprivation on fluency and prefrontal cortex function during divergent thinking. Frontiers in Human Neuroscience, 8, 214.

https://doi.org/10.3389/fnhum.2014.00214

Verdun, R. E., Karlseder, J. (2006). The DNA damage machinery and homologous recombination pathway act consecutively to protect human telomeres. Cell., 709-720. doi: 10.1016/j.cell.2006.09.034.

Victorelli, S., \& Passos, J. F. (2017). Telomeres and cell senescence - size matters not. EBioMedicine, 21, 14-20. https://doi.org/10.1016/j.ebiom.2017.03.027

Vizi, E. S. (1998). Receptor-mediated local fine-tuning by noradrenergic innervation of neuroendocrine and immune systems. Ann. N. Y. Acad. Sci., 851, 388-396. doi: 10.1111/j.1749-6632.1998.tb09012.x

Wang, H.-X., Wahlberg, M., Karp, A., Winblad, B., and Fratiglion, L. (2012). Psychosocial stress at work is associated with increased dementia risk in late life. Alzheimer's Dementia, 8, 114-120. doi: 10.1016/j.jalz.2011.03.001

Wang, H., Yu, M., Ochani, M., Amella, C. A., Tanovic, M., Susarla, S., et al. (2003). Nicotinic acetylcholine receptor $\alpha 7$ subunit is an essential regulator of inflammation. Nature 421, 384-388. Doi: 10.1038/nature01339

Williams, D. P., Koenig, J., Carnevali, L., Sgoifo, A., Jarczok, M. N., Sternberg, E. M., \& Thayer, J. F. (2019). Heart rate variability and inflammation: A meta-analysis of human studies. Brain, Behavior, and Immunity. 80, 219-226. https://doi.org/10.1016/j.bbi.2019.03.009

Williams G. C. (1957). Pleiotropy, natural selection, and the evolution of senescence. Evolution, 11(4), 398-411.

Wong, J. Y., De Vivo, I., Lin, X., Fang, S. C., \& Christiani, D. C. (2014). The relationship between inflammatory biomarkers and telomere length in an occupational prospective cohort study. PloS one, 9(1), e87348. https://doi.org/10.1371/journal.pone.0087348

Wong, L. S., Huzen, J., de Boer, R. A., van Gilst, W. H., van Veldhuisen, D. J., et al. (2011). Telomere length of circulating leukocyte subpopulations and buccal cells in patients with ischemic heart failure and their offspring. PLoS One, 6, e23118.

Wood, H. (2018). Peripheral inflammation could be a prodromal indicator of dementia. Nat Rev Neurol, 14, 127. https://doi.org/10.1038/nrneurol.2018.8

Woody, A., Hamilton, K., Livitz, I. E., Figueroa, W. S., and Zoccola, P. M. (2017b). Buccal telomere length and its associations with cortisol, heart rate variability, heart rate, and blood pressure responses to an acute social evaluative stressor in college students. Stress, 20, 249-257. doi: 10.1080/10253890.2017.1328494

Yang, Y., Paspalas, C. D., Jin, L. E., Picciotto, M. R., Arnsten, A. F., \& Wang, M. (2013). Nicotinic $\alpha 7$ receptors enhance NMDA cognitive circuits in dorsolateral prefrontal cortex. Proceedings of the National Academy of Sciences of the United States of America, 110(29), 12078-12083. https://doi.org/10.1073/pnas.1307849110

Yu, W. Y., Chang, H. W., Lin, C. H., \& Cho, C. L. (2008). Short telomeres in patients with chronic schizophrenia who show a poor response to treatment. Journal of psychiatry \& neuroscience: $J P N, 33(3), 244-247$.

Zalli, A., Carvalho, L. A., Lin, J., Hamer, M., Erusalimsky, J. D., Blackburn, E. H., et al. (2013). Shorter telomeres with high telomerase activity are associated with raised allostatic load 
bioRxiv preprint doi: https://doi.org/10.1101/2022.02 17.480574 this version posted February 22, 2022. The copyright holder for this

and impoverished psychosocial resources. Proc. Natl. Acad. Sci. U.S.A., 111, 45194524. doi: 10.1073/pnas.1322145111

Zhu, X., Han, W., Xue, W., Zou, Y., Xie, C., Du, J., \& Jin, G. (2016). The association between telomere length and cancer risk in population studies. Scientific Reports, 6 , 22243. https://doi.org/10.1038/srep22243

Zulli, R., Nicosia, F., Borroni, B., Chiara, A., Prometti, P., Donati, P., et al. (2006). QT dispersion and heart rate variability abnormalities in alzheimer's disease and in mild cognitive impairment. J. Am. Geriatr. Soc. 53, 2135-2139. doi: 10.1111/j.15325415.2005.00508.x 